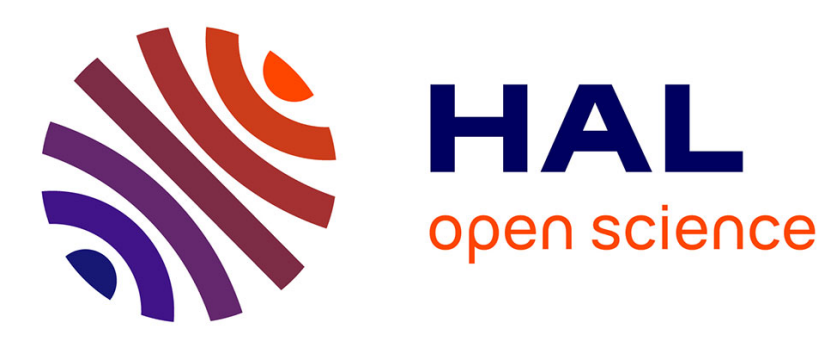

\title{
CHAPTER 5. Gases
}

D. Yi, B. Chaudret, Aikaterini Soulantika

\section{To cite this version:}

D. Yi, B. Chaudret, Aikaterini Soulantika. CHAPTER 5. Gases. Reducing Agents in Colloidal Nanoparticle Synthesis, Royal Society of Chemistry, pp.97-129, 2021, Nanoscience \& Nanotechnology Series, 10.1039/9781839163623-00097 . hal-03386395

\section{HAL Id: hal-03386395 https://hal.science/hal-03386395}

Submitted on 19 Oct 2021

HAL is a multi-disciplinary open access archive for the deposit and dissemination of scientific research documents, whether they are published or not. The documents may come from teaching and research institutions in France or abroad, or from public or private research centers.
L'archive ouverte pluridisciplinaire HAL, est destinée au dépôt et à la diffusion de documents scientifiques de niveau recherche, publiés ou non, émanant des établissements d'enseignement et de recherche français ou étrangers, des laboratoires publics ou privés. 
$1 \quad \mathrm{XX}$ Gases

2

3 D. Yia, B. Chaudret ${ }^{\mathrm{a}}$ and K. Soulantica ${ }^{\mathrm{a}^{*}}$

4 a LPCNO, Université de Toulouse, CNRS, INSA, UPS, 135 avenue de Rangueil,

531077 Toulouse, France.

$6 \quad{ }^{*}$ corresponding email address: ksoulant@insa-toulouse.fr

7

\section{$8 \quad$ ABSTRACT}

9 Dihydrogen and carbon monoxide have been used for many years for the reduction

10 of metals from their ores. These are the two gaseous reducing agents of choice for

11 the synthesis of metal nanoparticles starting from molecular precursors. Their

12 drawbacks (flammability and/or toxicity, use of high pressures) are counterbalanced

13 by an easy removal of the unreacted agents after reaction, and by the fact that they

14 leave no or few residues after use. Apart from acting as reducing agents, they can

15 act as shape directing agents and surface-active species, which influences their

16 structural features and their physical and chemical properties. Last but not least,

17 since during the nanoparticle formation they are present in a large excess, they can

18 be involved in homogenous or heterogeneous catalytic reactions that take place on

19 soluble metal compounds (precursors, intermediate species) or on the surface of the

20 nascent nanoparticles, respectively. These catalytic reactions may influence the

21 nanoparticle formation process and nanoparticle properties. 


\section{Introduction}

23 Gases, and in the first-place hydrogen, have long been used for the production of reduced metals in a finely divided form. Gas reagents are characterized by an easy diffusion in solids and solutions, despite the low solubility of e.g. hydrogen in many solvents. When employed as reducing agents for the formation of nanoparticles

27 (NPs), and depending on the precursor, they leave behind little or no residues and the excess reducing agent is easily separated by gas release. The reducing agent concentration is also easily controlled by the pressure applied, which in turn controls the kinetics of reduction of the precursors. The main drawbacks are associated to flammability and/or toxicity issues and to the use of high pressures. Nevertheless, for many metals, several routinely used non-gaseous reducing agents can also be toxic and/or flammable. In the same context, reduction by gaseous reagents can also be carried out at low, even atmospheric pressure, which reduces the risks associated to high pressure. For comparison sake, a champagne bottle is pressurized at 5-6, up to 8 bars. Although several other reducing gasses exist $\left(\mathrm{NH}_{3}, \mathrm{PH}_{3}, \ldots ..\right)$, their use in nanoparticle synthesis is practically non-existent. The reducing gases used in the synthesis of metal nanoparticles and discussed here are dihydrogen and carbon monoxide.

The formation of even the simplest colloidal nanocrystal is a complex process in which molecular and surface chemistry operate simultaneously and it is well documented that nanocrystal morphology depends both on thermodynamic and kinetic factors that operate during nanoparticle formation processes. ${ }^{1}$ Indeed, at the molecular level, the reducing agents control the rate at which metal atoms are produced from a precursor. Consequently, $\mathrm{H}_{2}$ or $\mathrm{CO}$ pressure may affect the nucleation and growth kinetics by controlling the rate at which "active monomers" 
are: i) liberated from the precursor, and ii) deposited on the growing nanocrystals. In this respect, $\mathrm{H}_{2}$ and $\mathrm{CO}$ being mild reducing agents enable a fine control of the reduction rate either by modulating the gas pressure or by playing with the temperature. Additional effects can be expected for $\mathrm{H}_{2}$ and $\mathrm{CO}$ since it is known that small molecules, including gaseous molecules can modify the surface free energy (thermodynamic effect), or impact metal atom diffusion (kinetic effect) on the nanocrystal facets. ${ }^{2}$ Thus, they can act as stabilizers themselves, by selectively passivating certain facets of the nascent crystals, or they can even facilitate elimination of other passivating species during growth. The reducing agents may not only reduce the metal center but also the ligands (either native or added) and even the solvent in which the reaction takes place, which can affect the system in disparate ways. Indeed, metals either in their molecular form or as solids can behave as catalysts. The reactions under $\mathrm{H}_{2}$ or $\mathrm{CO}$ can result in hydrogenation or carbonylation reactions that are not desired or not anticipated in the first place.

The purpose of this chapter is not to give a comprehensive list of all the cases in which gas reductants have been employed in the synthesis of metal NPs. We will instead focus on cases where employing gas reducing agents "makes a difference", that is, examples in which $\mathrm{H}_{2}$ and $\mathrm{CO}$ present advantages or drawbacks and cases in which gas reducing agents have been identified as decisive for the development of interesting features or properties for the resulting metal NPs. Among them a great part is devoted to representative cases in which effects of the reducing gas on the nanoparticle morphology are reported. While the interplay among different factors does not always allow to affirm the role tentatively attributed to the reducing agent, in some cases, specific studies have demonstrated that indeed the gas reducing agent is important in determining nanoparticle morphology either through kinetic or 
thermodynamic control of the nanoparticle formation. In this respect, we will present some examples of formation of nanoparticles by reduction or decomposition of molecular precursors using hydrogen. Pure inorganic salts will be treated first.

Organometallic and metal-organic complexes will be treated simultaneously in this chapter since the difference is sometimes shallow between these two types of species. We will then describe the formation of NPs by interaction with CO leading either to reduction of the complex or native ligand substitution followed by metal growth.

\section{Hydrogen}

Hydrogen can be employed as a reducing agent for a large variety of metals. Indeed, it has been used for many years at an industrial scale for the production of ultrapure fine metal powders from their oxides, chlorides, sulphides, sulphates etc in high yields (>99\%). ${ }^{3}$ Nowadays, there is a renewed interest for hydrogen in the field of metallurgy where it is shown that hydrogen coming from renewable energies may be the future of this industry, given the enormous carbon footprint of the present metallurgical processes. In conventional steelmaking processes, $\mathrm{CO}_{2}$ gas is produced when iron ore is reduced with $\mathrm{CO} . \mathrm{H}_{2}$ reduction produces $\mathrm{H}_{2} \mathrm{O}$ instead of $\mathrm{CO}_{2}$, thus, this method can be regarded as more environmentally friendly. ${ }^{4}$ $\mathrm{H}_{2}$ is a reducing agent of intermediate strength, ${ }^{5}$ i.e. stronger than polyols and milder than sodium borohydride. The reduction of a metal by $\mathrm{H}_{2}$ can be represented by equation (1).

$2 \mathrm{M}^{\mathrm{n}+}+\mathrm{nH}_{2} \rightarrow 2 \mathrm{M}^{0}+2 \mathrm{nH}^{+}(1)$

The above equation can be shown as two half cells

$\mathrm{M}^{\mathrm{n}}+\mathrm{ne} \rightarrow \mathrm{M}^{0}(2)$ 
$\mathrm{H}_{2} \rightarrow 2 \mathrm{H}^{+}+2 \mathrm{e}(3)$

98 The reduction is thermodynamically feasible when $\Delta G\left(\Delta G_{\mathrm{H} 2}-\Delta G_{M}\right)$ is lower than

99 zero. Since $\Delta G$ is related to the reduction potential $(E), E_{\mathrm{H} 2}$ should be larger than $E_{\mathrm{M}}$

100 for the reduction to take place $\left(\Delta G-n F E_{c e l l}\right)$. $E_{\mathrm{H} 2}$ depends on the $\mathrm{pH}$ and $E_{\mathrm{M}}$ on the

101 metal (oxidation state, coordination sphere, complex stability or lability), therefore,

102 under appropriate conditions, it is possible to reduce even easily oxidizable metals

103 with hydrogen. Nowadays, hydrogen constitutes an ideal reducing agent, routinely

104 used both in industry and in academic research for the reduction of nanoparticles of

105 heterogeneous catalysts after their immobilization on a support and calcination. This

106 use is outside the scope of the present chapter. Here we will discuss the formation of

107 colloidal metal nanoparticles in solution, starting from molecular precursors.

108 Hydrogen has been employed by the pioneers of colloidal chemistry who used it for

109 the production of platinum metal nanocatalysts. Friedrich F. Nord has described this

110 methodology to prepare platinum metal colloids ( $\mathrm{Pd}, \mathrm{Pt}, \mathrm{Rh}, \mathrm{Ir})$ used as catalysts for

111 the hydrogenation of various substrates. ${ }^{6-9}$ The advantage was the direct formation

112 of colloidal catalysts by reduction of the metal salt in the reaction mixture containing

113 the substrates to be catalytically hydrogenated. Additionally, no residues that could

114 contaminate the surface of metal nanoparticles were left behind after its use. Since

115 then, a plethora of metal NPs have been prepared by using $\mathrm{H}_{2}$ to reduce all types of

116 compounds - metal salts, metal-organic and organometallic complexes.

117 While many theories exist about the formation mechanism of nanoparticles, a great

118 majority of the reports dealing with the synthesis of NPs do not focus on details

119 regarding the reduction mechanism at the molecular level. Nevertheless, reducing a

120 molecular metal species by hydrogen implies an interaction of the gas molecules

121 with the metal compound under consideration. It is thus logic to assume that 
122 oxidative addition and reductive elimination, which are well-known processes in

123 molecular chemistry, are operative during nanoparticle synthesis involving $\mathrm{H}_{2}$

124 reduction. The formation of classical metal hydrides is well documented ${ }^{10}$ for almost

125 all transition metals. It is therefore expected that hydrides are formed also in the first

126 steps of nanoparticle formation during hydrogen reduction of metal precursors.

127 Subsequently, a series of reactions (reductive eliminations, proton transfers)

128 involving removal and possible transformation of native ligands can produce zero-

129 valent unstable metal species. According to the LaMer classical nucleation theory, ${ }^{11}$

130 clustering of these species could form the first stable solid entities during the

131 nucleation step and the resulting seeds would grow during the growth step. As soon

132 as the solid phase is formed, the interaction of the metal surface comes also into

133 play. ${ }^{12}$ Many metals are efficient hydrogenation catalysts and as soon as the solid

134 phase appears, autocatalytic reductions can proceed on the metal surface in a

135 process involving adsorption and dissociation of $\mathrm{H}_{2}$. Indeed, Finke and Watzky have

136 proposed a two-step mechanism for the growth of metal nanoparticles, where a slow

137 continuous nucleation $\left(A \rightarrow B\right.$, rate constant $\left.k_{1}\right)$ is followed by fast autocatalytic

138 surface growth $\left(\mathrm{A}+\mathrm{B} \rightarrow 2 \mathrm{~B}\right.$, rate constant $\left.k_{2}\right) \cdot{ }^{13,14}$ This mechanism was based on

139 monitoring the kinetics of the nanoparticle formation through the cyclohexene

140 hydrogenation as a "reporter" reaction (Scheme 1). 


$$
\begin{aligned}
x & {\left[A \stackrel{k_{1}}{\rightarrow} B\right] } \\
1-x & {\left[A+B \stackrel{k_{2}}{\rightarrow} 2 B\right] } \\
\sim 1400 & {\left[B+\widehat{B}+\mathrm{H}_{2} \stackrel{k_{3}}{\rightarrow} B+\widehat{S}\right] }
\end{aligned}
$$

144 Scheme (1). Generalized two-step formation mechanism and the corresponding rate constants $k_{1}$ and $k_{2}$. Step (1) represents the nucleation; A corresponds to the organometallic precursor. Step (2) corresponds to the growth; B is a catalytically active atom on the surface of the metal. The reaction is monitored by the fast cyclohexene "reporter reaction" (3). Reproduced from Ref. 14 with permission from ACS, Copyright 1997.

151 This generalized mechanism was proposed in the mid-nineties. In the original paper

152 Finke et al. showed that the complex $\left[\left(\mathrm{Bu}_{4} \mathrm{~N}\right)_{5} \mathrm{Na}_{3}\left[(\mathrm{COD}) \mathrm{Ir} . \mathrm{P}_{2} \mathrm{~W}_{15} \mathrm{Nb}_{3} \mathrm{O}_{62}\right]\right.$ associating an organometallic iridium moiety to an hetero polyanion could be reduced under mild conditions by $\mathrm{H}_{2}(2.7 \mathrm{~atm})$ at room temperature affording polyanion decorated $\mathrm{Ir}$ NPs. ${ }^{13}$ Two sizes were obtained: $2 \mathrm{~nm}$ when the hydrogenation was carried out in the presence of excess cyclohexene, as part of a catalytic test, and $3 \mathrm{~nm}$ when the reaction was carried out in the absence of excess olefins. Interestingly, the authors claim the absence of hydrides at the surface of their catalyst. This and related systems were extensively studied by Finke over the years. The Finke-Watzky mechanism, which involves a slow nucleation and an autocatalytic growth (i.e. the

161 decomposition of the precursor over the growing metal surface), was initially based 
162 on thorough kinetic studies on $\mathrm{Ir}$, but it is proposed to be operational in a more

163 general frame, for transition metal nanoclusters formed under $\mathrm{H}_{2}$ and related

164 reducing agents. ${ }^{14}$ This system was used in different hydrogenation reactions,

165 including for example a very active system for acetone reduction. ${ }^{15}$ It was also

166 extended to the preparation of stable rhodium nanoparticles of ca. $4 \mathrm{~nm}$ and to their

167 use for the hydrogenation of cyclohexene..$^{16}$

\subsection{Metal salts}

170 Metal salts have been mainly used as precursors in syntheses performed in polar

171 media, including ionic liquids. ${ }^{17}$ Alternatively, they have been used in mixtures of

172 polar/nonpolar solvents in the presence of a phase transfer agents (i.e. long chain ammonium halides). In classical inorganic salts the metal centers are more electron deficient than in metal-organic and organometallic compounds. $\mathrm{H}_{2}$ has been used mainly with noble metal salts. Classical salts of low reduction potential metals are not used as precursors with $\mathrm{H}_{2}$ under the usual conditions employed in wet-chemistry NPs synthesis. It is noteworthy that $\mathrm{H}_{2}$ is not used to prepare NPs of one of the most easily reducible metals, Au. This is presumably due to the easy reduction of $\mathrm{Au}(\mathrm{III})$ salts that are the most popular salt precursors for Au NPs, using non-gaseous reductants. On the other hand, the difficult oxidative addition of $\mathrm{H}_{2}$ to produce

181 hydride intermediates does not favor reduction of $\mathrm{Au}(\mathrm{I})$ precursors by $\mathrm{H}_{2}$. In fact,

182 pathways to Au-H formation remain elusive, except under some extreme conditions. ${ }^{18}$

184 Metal salts of $\mathrm{Pd}, \mathrm{Pt},{ }^{6} \mathrm{Rh}^{7,8} \mathrm{Ir},{ }^{9}$ have been extensively employed for many years for the synthesis of hydrogenation nanocatalysts. The reductions were performed in

186 water in the presence of polyvinyl alcohol and they were efficient under atmospheric 
$187 \mathrm{H}_{2}$ pressure and room temperature, provided that $\mathrm{NaOH}$ was added in order to

188 convert the salts to the easily reducible hydroxides. Based on these results and by

189 adaptation of the same method, tetrahedral and cubic nanocrystals were obtained

190 from $\mathrm{K}_{2} \mathrm{PtCl}_{4}$ and sodium polyacrylate as a stabilizing agent by El Sayed et al. ${ }^{19}$ This

191 was an important progress in the synthesis of shape-controlled Pt nanocrystals,

192 despite the fact that in all the studied cases, a mixture of tetrahedral and cubic NPs

193 was present with ratios of each morphology depending on the Pt/capping agent ratio.

194 Nanocrystal shape is among the characteristics that influence nanoparticle physical

195 and chemical properties, to the point that some applications critically depend on it. ${ }^{20-}$

$196{ }^{23}$ Later, it was concluded that a competition between the reduction and the capping

197 processes modulates the relative deposition rates on the $\{100\}$ and $\{111\}$ facets, and

198 therefore the shape of the nanocrystals ${ }^{24}$ which is pivotal for their catalytic properties

199 in hydrogenation reactions. ${ }^{22,25}$

200 Indeed, despite the fact that shape-controlled NPs are obtained in numerous

201 syntheses with $\mathrm{H}_{2},{ }^{19,25} \mathrm{H}_{2}$ is not routinely considered among the parameters that

202 could influence nanocrystal shape. Below, we present some non-exhaustive cases in

203 which $\mathrm{H}_{2}$ has been identified as an additional factor that could be involved in the

204 shape control of metal nanocrystals.

205 Teranishi et al. reduced $\mathrm{H}_{2} \mathrm{PtCl}_{6}$ in the presence of various amounts of sodium

206 polyacrylate and poly(N-vinyl-2-pyrrolidone) (PVP). The dominant shape of Pt NPs

207 was controlled by changing the reduction rate of $\mathrm{Pt}(\mathrm{IV})$ ions through two different

208 reducing agents: methanol and $\mathrm{H}_{2} \cdot{ }^{26} \mathrm{~A}$ slow reduction by dihydrogen was proposed

209 to form tetrahedral nuclei initially, while a fast reduction by methanol produced

210 truncated octahedral nuclei. The final Pt NPs preserve the shape of the Pt nuclei at a 
211 high polymer concentration, whereas at a low polymer concentration, the Pt NP

212 shape evolves from tetrahedron to truncated octahedron and finally to cubic.

213 Fu et al. have compared the reduction of three precursors $\mathrm{K}_{2} \mathrm{PtCl}_{4}, \mathrm{~K}_{2} \mathrm{PtCl}_{6}$ and

$214 \mathrm{~K}_{2}\left[\mathrm{Pt}\left(\mathrm{C}_{2} \mathrm{O}_{4}\right)_{2}\right] .{ }^{27}$ The slower reduction rate of $\mathrm{K}_{2}\left[\mathrm{Pt}\left(\mathrm{C}_{2} \mathrm{O}_{4}\right)_{2}\right]$ was identified as a

215 decisive parameter for the production of a higher shape selectivity to nanocubes

216 (more than 90\%) as compared to the other two precursors.

217 In another work that illustrates the possible importance of $\mathrm{H}_{2}$ even when different

218 reducing agents are employed, Somorjai et al. have pointed out that the molecular

$219 \mathrm{H}_{2}$ produced upon $\mathrm{NaBH}_{4}$ reaction with $\mathrm{H}_{2} \mathrm{O}$ was the real responsible for the shape

220 control of $\mathrm{Pt}$ nanocrystals produced from $\mathrm{K}_{2} \mathrm{PtCl}_{4}$ and tetradecyltrimethylammonium

221 bromide as a surface stabilizer. ${ }^{28}$ Interestingly, in situ $\mathrm{H}_{2}$ gas generation from $\mathrm{NaBH}_{4}$

222 has been theoretically and experimentally identified by Petit et al. as an important

223 parameter for the formation of $\mathrm{Pt}$ nanocubes from $\mathrm{H}_{2} \mathrm{PtCl}_{6}$ thanks to the preferential

224 interaction of $\mathrm{H}$ with the $\{100\}$ facets. ${ }^{29,30}$ While $\mathrm{H}$ stabilizes selected $\mathrm{Pt}$ facets, only

225 ill-shaped Pd nanoparticles were prepared by the same method from $\mathrm{H}_{2} \mathrm{PdCl}_{4}$. In that

226 case, it was suggested that $\mathrm{H}_{2}$ induced the formation of the amorphous $\mathrm{PdH}_{\mathrm{x}}$ phase

227 by dissociation of $\mathrm{H}_{2}$ on the metal surface and diffusion of atomic $\mathrm{H}$ in the crystal

228 lattice. $^{29}$

229 Metal salts have also been reduced under $\mathrm{H}_{2}$ in non-polar solvents, albeit, in the

230 presence of long chain organic stabilizers, mainly amines, that allowed precursor

231 solubilization by formation of different precursor/s, even if this is not always

232 discussed. This method has given access to more complex shapes. For example,

233 Lacroix et al., using $\mathrm{H}_{2} \mathrm{PtCl}_{6}$ in pure oleylamine under an $\mathrm{H}_{2}$ atmosphere,

234 synthesized cubic dendrites, planar tripods, and fivefold stars at $150{ }^{\circ} \mathrm{C}$. The control

235 of experimental parameters such as Pt concentration (Figure 1), reaction 
236 temperature, and $\mathrm{H}_{2}$ pressure, allowed manipulating the reaction kinetics, and

237 through this, the nature of seeds which led to the different morphologies. Noticeably,

238 oleylamine, used as solvent and as a stabilizer, was reduced to octadecylamine

239 during the NPs synthesis due to catalytic hydrogenation by Pt. ${ }^{31}$
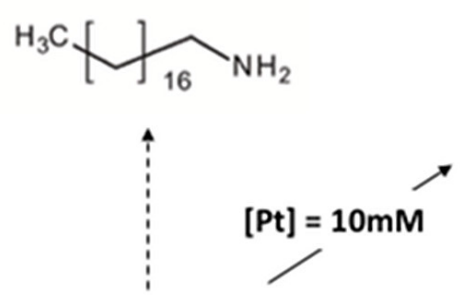

$\mathrm{H}_{2} \mathrm{PtCl}_{6}+$ Oleylamine

3 bar $\mathrm{H}_{2}, 150^{\circ} \mathrm{C}$

$[\mathrm{Pt}]=2 \mathrm{mM}$

240

241

242

243

244

245

246

247

248

249

250

251
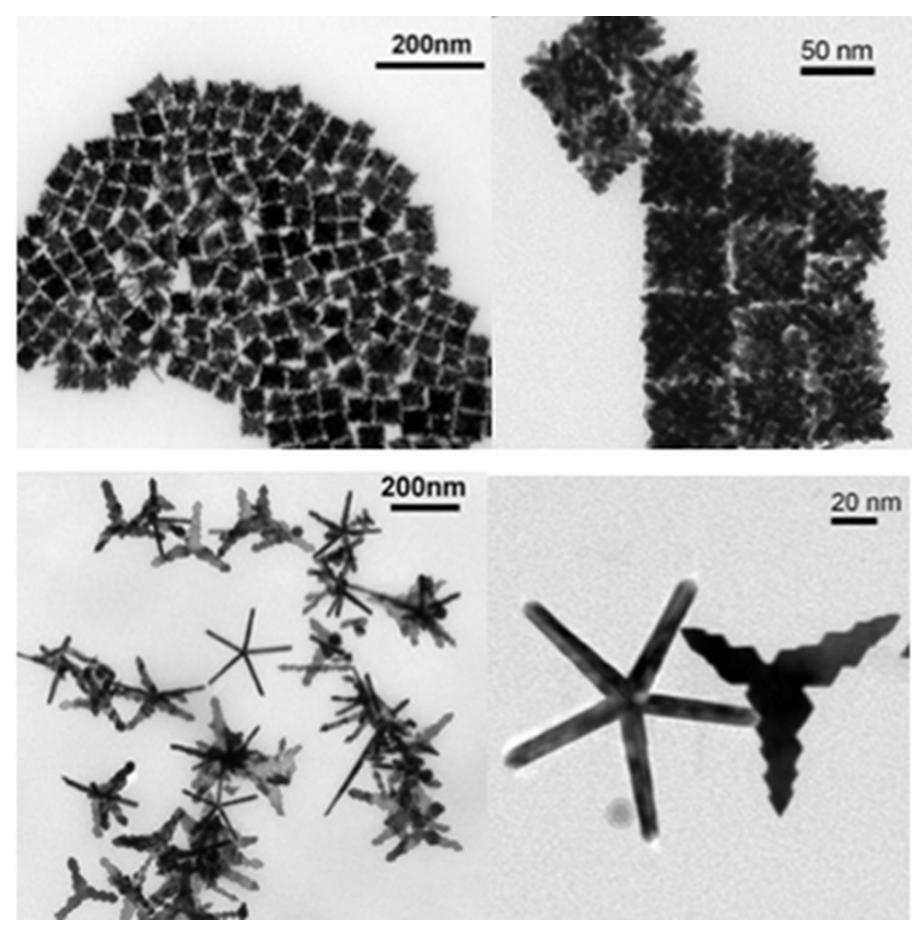

Figure 1. Platinum nano-objects obtained by reduction of $\mathrm{H}_{2} \mathrm{PtCl}_{6}$ at $150{ }^{\circ} \mathrm{C}$ under $\mathrm{H}_{2}$ (3 bar) employing different precursor concentrations.

In another work, $\mathrm{PtCl}_{2}$ which can be reduced more easily than $\mathrm{H}_{2} \mathrm{PtCl}_{6}$, has been used in toluene in the presence of an excess of octadecylamine. ${ }^{32} \mathrm{Pt}$ concave cubes exposing $\{110\}$ crystallographic facets have been thus synthesized at an impressively low temperature $\left(20^{\circ} \mathrm{C}\right)$. The formation process can be described by a subtle balance between Pt atom production and deposition on the vertices of cubic seeds and diffusion of these atoms to more stable locations on the seed. Several conditions have to be fulfilled, including the use of low temperature, of a sufficient amount of the long chain amine, the use of $\mathrm{PtCl}_{2}$ which produces easily reducible 
species upon reaction with the amine and the use of $\mathrm{H}_{2}$ as a mild reducing agent that

can reduce the Pt reservoir at "just the right rate" to allow its diffusion along the

edges, a prerequisite for the formation of the cubes enclosed by $\{110\}$ facets.

Increasing the temperature increases the rate of both "monomer" production and

diffusion of the Pt atoms, however, "monomer" production seems to be favored over

257

diffusion, since at $60{ }^{\circ} \mathrm{C}$, octopods are obtained due to the fast deposition of Pt on the vertices of the cubic seeds (Figure 2).

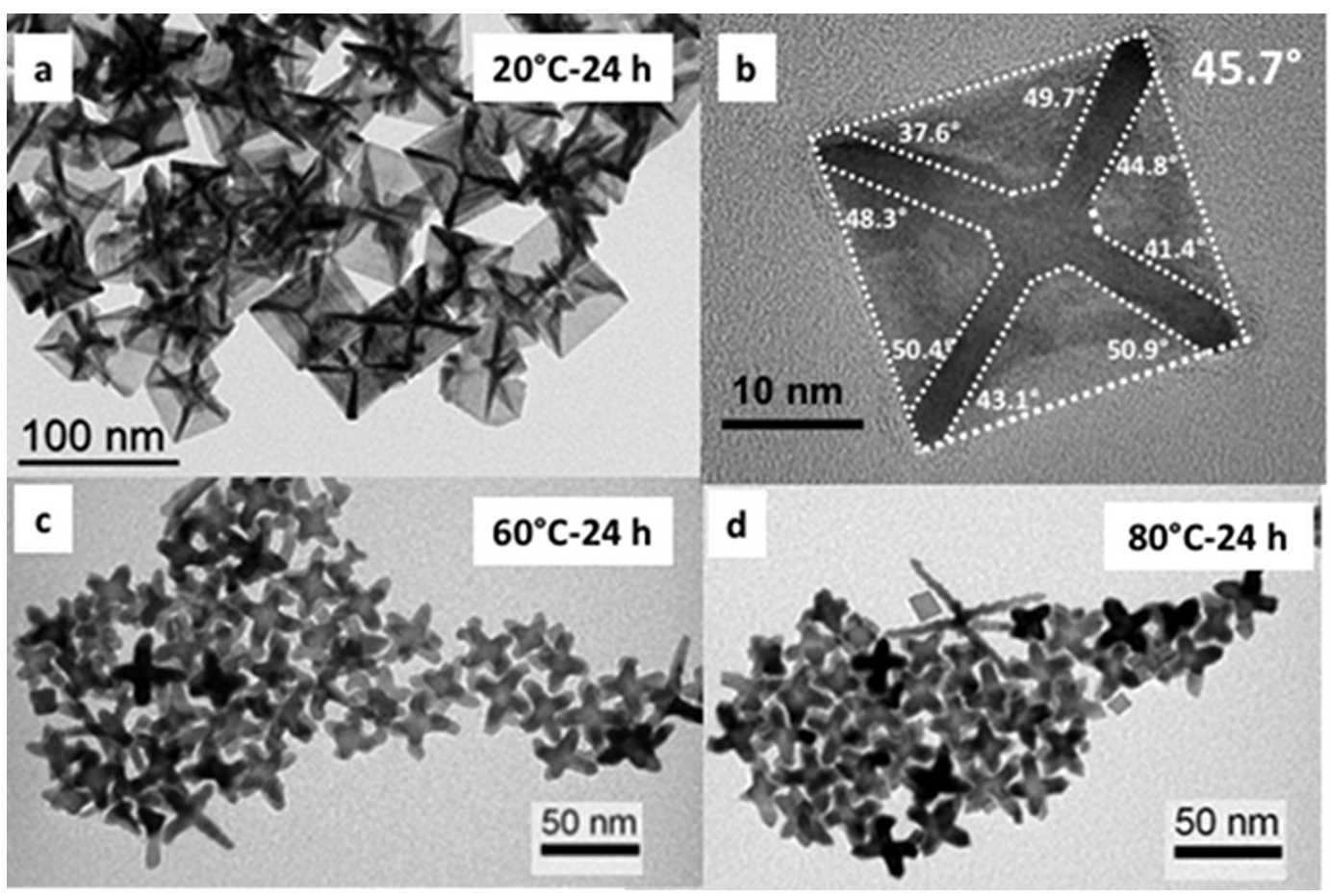

Figure 2. Platinum nano-objects obtained by reduction of $\mathrm{PtCl}_{2}$ under $\mathrm{H}_{2}$ (3 bar) at image of an individual Pt nanocube with the measured dihedral angles; the mean angle of $46^{\circ}$ indicates that the exposed facets are of the $\{110\}$ type. 
268 The octadecylamine used as a stabilizer in large excess can also act as reducing

269 agent, but in the absence of $\mathrm{H}_{2}$, no concave nanocubes were obtained. In cases

270 where more than one species are present in the reaction medium, reduction may

271 result from more than one source. This is true also for the exact role of other species

272 that can be formed in solution from the starting materials $\left(\mathrm{PtCl}_{2}\right.$ and octadecylamine,

273 in the above-mentioned example). In addition, when in excess, the amine should trap

274 the $\mathrm{HCl}$ formed during the reduction as ammonium chloride. In fact, halides present

275 in many salt precursors and ammonium halide stabilizers added from the beginning

276 or formed during the reaction, are among the species that can strongly adsorb on

277 nanoparticle surfaces in a selective manner depending on the crystallographic

278 orientation of the facets. ${ }^{33}$

279

\subsection{Organometallic and metal-organic compounds}

281 Organometallic compounds involve at least one ligand linked to the metal center

282 through M-C bonds whereas metal-organic complexes contain ligands that are linked

283 through heteroatoms ( $\mathrm{P}, \mathrm{N}, \mathrm{O}, \mathrm{S}, \mathrm{Cl}$, etc.). Such coordination compounds that do not contain M-C bonds like metal acetylacetonates, carboxylates etc., are the most widely used precursors for metal NPs. For colloidal metal nanoparticle synthesis, $\mathrm{H}_{2}$ is an ideal reducing agent when the reaction has to be performed in organic solvents, in which other reducing agents cannot be used due to solubility issues.

288 This is the case for almost all organometallic compounds and a great number of coordination compounds for which solubility or chemical stability issues do not allow the use of water-soluble reducing agents.

291 Reduction of such compounds in the presence of a variety of stabilizing agents and

292 under diverse reaction conditions has allowed a fine control over size, shape, 
chemical composition and specific configuration of multicomponent nanostructures

294 (random alloys, intermetallics, core@shell, Janus, etc.). The ligands present on the starting precursors (native ligands) can be displaced completely or partially by the added stabilizing agents. It is therefore important to keep in mind that most of the times, the native ligands stay in solution and are part of the parameters that can affect the reaction outcome. The rich coordination chemistry and its importance in the formation and the properties of metal NPs is outside the scope of this chapter and has been reviewed elsewhere, ${ }^{34,35,36}$ but it is worth noting that added stabilizers provide protection against coalescence and, depending on their nature and concentration, they can control nanoparticle size and shape though surface passivation during growth. Added stabilizing ligands may react with the precursors, to transform them into new molecular species acting as metal reservoir. This in turn will affect the course of the reaction (nucleation and growth steps) and its outcome. Therefore, the "real" precursors arise from reactions between the stabilizing agents and the initially introduced molecular metal complex. The different ligands (native or added) present in solution may also participate to equilibria that take place both among the molecular species involved in the reaction process and on the surface of NPs. Finally, ligands, native or added, can be transformed during the whole process

311 of nanoparticle formation. For instance, olefinic bonds can be hydrogenated (e.g.

312 cyclooctadiene hydrogenation to cyclooctane, oleyl amine to octadecylamine, partial

313 or complete hydrogenation of aryl substituents of phosphine), native ligands can react with incoming stabilizing agents (e.g. incoming carboxylic acids reaction with native silylamide ligands, formation of ammonium salts from amine stabilizing agents

316 and native halides), carboxylates can be decarboxylated, etc. 


\subsubsection{Organometallic compounds}

319 Organometallic compounds with metal centers in various formal oxidation states

320 have been employed as precursors for the synthesis of a large variety of mono- and

321 bi-metallic NPs through decomposition by hydrogen that may, or not, involve

322 reduction of the metal centre..$^{34,37-39}$

323 The use of organometallic compounds, lacking in their coordination sphere any

324 ligand that could stabilize efficiently the final nanoparticle surface, constitutes an

325 important knob of controlling the chemical and physical properties by addition of

326 appropriate ligands. This is the case of organometallic complexes containing a metal

327 center, in zero or low formal oxidation state, coordinated exclusively to hydrocarbon

328 ligands through metal-carbon bonds (sigma bonds, pi bonds or a combination of

329 both). Some non-exhaustive examples of metal NPs that have been prepared by this

330 class of organometallic precursors by reaction with $\mathrm{H}_{2}$ include: $\mathrm{Ru}$ from

$331[\mathrm{Ru}(\mathrm{COD})(\mathrm{COT})] ;(\mathrm{COD}=1,5$ cyclooctadiene, $\mathrm{COT}=1,3,5$ cyclooctatriene $),{ }^{40} \mathrm{Pt}$

332 from $\left[\mathrm{Pt}(\mathrm{Me})_{2}(\mathrm{COD})\right],{ }^{41}$ and $\left[\mathrm{Pt}(\mathrm{dba})_{\mathrm{x}}\right] ;$ ( $\mathrm{dba}=$ dibenzylidene-acetone $),{ }^{42} \mathrm{Pd}$ from

$333\left[\mathrm{Pd}_{2}(\mathrm{dba})_{3}\right],{ }^{43} \mathrm{Rh}$ from $\left[\mathrm{Rh}(\text { allyl })_{3}\right],{ }^{44} \mathrm{Cu}$ from $[\mathrm{Cu}(\text { mesityl })]_{5},{ }^{45} \mathrm{Ni}$ from $\left[\mathrm{Ni}(\mathrm{COD})_{2}\right],{ }^{46}$

334 Co from $[\mathrm{Co}(\mathrm{COE})(\mathrm{COD})]\left(\mathrm{COE}=\eta^{3}-\mathrm{C}_{8} \mathrm{H}_{13}\right),{ }^{47} \mathrm{Re}$ from $\left[\mathrm{Re}_{2}(\right.$ allyl $\left.) 4\right],{ }^{48} \mathrm{Al}$ from

$335\left[\left(\mathrm{AlCp}^{*}\right)_{4}\right]\left(\mathrm{Cp}^{*}\right.$ : penta-methylcyclopentadienyl), ${ }^{49}$ or $\mathrm{Zn}$ from $\left[\mathrm{Zn}\left(\eta^{1} \mathrm{Cp}{ }^{*}\right)\left(\eta^{5} \mathrm{Cp} p^{*}\right)\right] .{ }^{50}$

336 During nanoparticle formation, depending on the oxidation state of the metal and on

337 the ligand type, hydrogen may displace the native ligands with or without reducing

338 them (metal in zero oxidation state), or reduce both metal and native ligands. As a

339 result of the treatment with $\mathrm{H}_{2}$, "naked" metal atoms and hydrocarbons with no or

340 very low stabilizing ability are produced. The hydrides present on the metal surface cannot stabilize the NP which leads to aggregation of the resulting "naked" metallic atoms and finally in the formation of bulk metal. Therefore, this type of precursors 
cannot be employed without the presence of stabilizing agents, which are introduced

344 in the reaction medium before the reduction starts. Thus, nanoparticle stabilization is

345 achieved by a large variety of stabilizing agents, ${ }^{37,51-56}$ which are added in the

346 reaction mixture during synthesis (amines, phosphines, acids, N-heterocyclic

347 carbenes) and even by certain coordinating solvents (e.g. THF (tetrahydrofuran),

348 alcohols). ${ }^{51,57}$ The possibility that some added stabilizing ligands react with

349 hydrogen, particularly when the reactions are performed at relatively high

350 temperatures, ${ }^{43,44,53,58-60}$ has to be considered.

351 Below we present some examples that highlight the above-mentioned effects that

352 have to be taken into account when reducing organometallic compounds with $\mathrm{H}_{2}$.

353 Perhaps the most representative example of organometallic precursors, is the

354 ruthenium(0) complex $[\mathrm{Ru}(\mathrm{COD})(\mathrm{COT})]$ that has been used for the formation of pure

355 Ru and bimetallic Ru containing NPs. ${ }^{34}$ As outlined in Scheme 2, upon

$356[\mathrm{Ru}(\mathrm{COD})(\mathrm{COT})]$ treatment with dihydrogen at room temperature, hydrogenation of

357 the olefinic bonds of the COD and COT ligands produces cyclooctane and "naked"

358 Ru atoms, which subsequently form NPs that cannot be stabilized by the produced 359 cyclooctane.

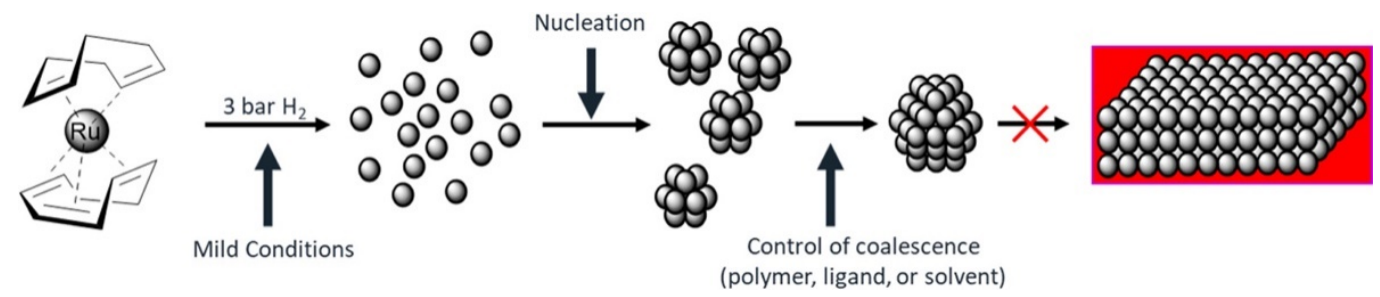

362 Scheme 2. Outline of the decomposition under $\mathrm{H}_{2}$ of $\mathrm{Ru}(\mathrm{COD})(\mathrm{COT})$. Reproduced

363 from Ref. 50 with permission from ACS, Copyright 2018. 
365 Compared to other metal NPs, the surface state of Ru NPs has been extensively

366 studied due to the fact that in addition to the classical nanoparticle characterization

367 techniques, liquid- and solid-state NMR studies are particularly well-adapted for this

368 metal, thanks to the absence of magnetic perturbations (Knight shift). The nature and

369 concentration of ligand influence the size and the shape of the NPs. ${ }^{51,53}$ It is worth

370 mentioning that, in the presence of amine ${ }^{61}$ or carboxylate ligands, ${ }^{62}$ mobile surface

371 hydrides are present on the surface of the as obtained Ru NPs. They can exchange

372 with $\mathrm{H}_{2}$ or $\mathrm{D}_{2}$ in the gas-phase and even perform $\mathrm{H}-\mathrm{D}$ exchange reactions on the

373 aliphatic chains of the ancillary ligands.

374 Surface hydrides are active species involved in a number of heterogeneous catalytic

375 reactions. Their presence on Ru NPs has been detected and quantified by titration

376 with $D_{2}$ and with olefins. ${ }^{61,63}$ Analysis by gas chromatography has demonstrated the

377 presence of 1.2 and $1.5 \mathrm{H}$ per surface Ru atom, depending upon the system. The

378 observation and location of these hydrides was more challenging, in particular the

379 question of their presence inside the particles or on their surface. For this purpose,

380 the hydrides were exchanged with deuterium and the particles were characterized by

381 static solid state ${ }^{2} \mathrm{D}$ NMR. Thanks to the quadrupolar splitting, which is related to the

382 degree of anisotropy experienced by a quadrupolar nucleus, and the use of model

383 mononuclear compounds to determine the splitting expected for Ru-D Ru-D $\mathrm{D}_{2}$ bonds

384 and clusters containing a $\mu^{2}$-, $\mu^{3}$ - or $\mu^{6}$ - bridging deuteride, it was possible to observe

385 the presence of surface deuterides and to attribute them a mode of coordination on

386 the particles surface ${ }^{64,65}$ (Figure 3). 


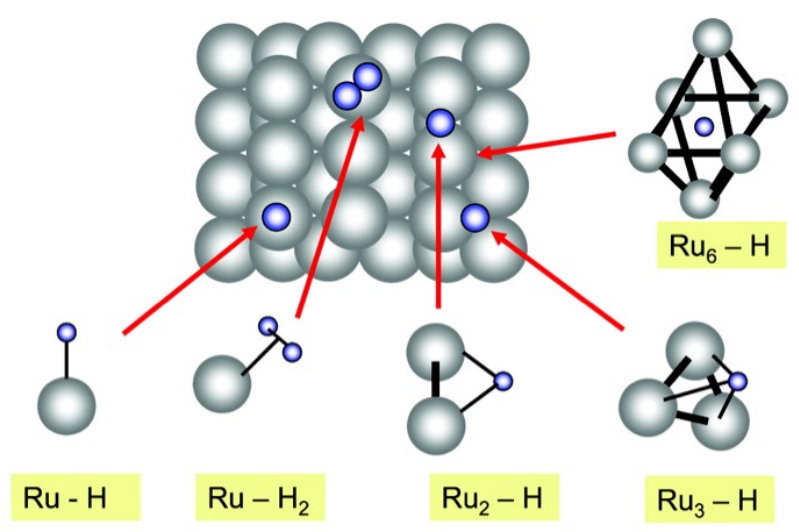

387

388 Figure 3. Hydrogen species on Ru metal surfaces. Adapted from Ref. 64 with permission from ACS, Copyright 2010.

390

391 Interestingly, this technique evidences the mobility of surface deuterides and the

392 freezing temperature of the deuterium mobility on the particles surface was found

393 dependent upon the stabilizer used. Thus, strong ligands such as diphosphines

394 induce freezing near $273 \mathrm{~K}$ whereas the freezing temperature is around $200 \mathrm{~K}$ for $\mathrm{Ru}$

395 NPs stabilized by hexadecylamine (HDA) ${ }^{65}$ and $25 \mathrm{~K}$ for Ru NPs included in a

396 MOF. ${ }^{66}$ According to the quadrupolar splitting, all modes of coordination were

397 observed on Ru/HDA, whereas hydrides were exclusively terminal for Ru/MOF.

398 All hydride containing Ru NPs were found to be very active hydrogenation

399 catalysts. $^{67} \mathrm{~N}$-heterocyclic carbenes have been found to be particularly efficient

400 ligands for ruthenium leading to very stable but reactive nanoparticles

401 accommodating between 1 and 1.5 hydride per Ru surface. ${ }^{55}$

402 Stabilizing ligands can undergo transformation due to parallel reactions. For

403 instance, it was shown that during the decomposition of $[\mathrm{Ru}(\mathrm{COD})(\mathrm{COT})]$ under $\mathrm{H}_{2}$ in

404 THF in the presence of carboxylic acid ligands, CO was found on the surface of the

405 NPs. This CO arises both from THF decomposition and from carboxylic acid 
406 decarbonylation. ${ }^{68}$ The latter occurred at surprisingly low temperature (room

407 temperature). Catalytic decarbonylation of carboxylic acids in the presence of

408 dihydrogen usually occurs at much higher temperatures and pressures, suggesting

409 an unanticipated high reactivity of undercoordinated Ru species that are formed

410 during the decomposition of $[\mathrm{Ru}(\mathrm{COD})(\mathrm{COT})]$ in the presence of $\mathrm{H}_{2}$ and carboxylic

411 acids. Another example is the partial hydrogenation of fullerene ligands catalyzed by

412 Ru NPs prepared from $[\mathrm{Ru}(\mathrm{COD})(\mathrm{COT})]$ and fullerene under $\mathrm{H}_{2} .{ }^{59}$ Partial or

413 complete catalytic hydrogenation of the aryl rings of phosphine ligands has also

414 been demonstrated through deuteration experiments. ${ }^{60}$

415 The Ru NPs prepared through the organometallic method are also very active for the

416 selective labelling of organic molecules of interest through $\mathrm{C}-\mathrm{H}$ activation. ${ }^{69}$ This

417 method was extended to the unprecedented simple enantiospecific $\mathrm{C}-\mathrm{H}$

418 activation/deuteration of stereogenic centers, located in $\alpha$-position of a heteroatom of

419 amino acids and peptides through a four-membered dimetallacycle as a novel key

420 intermediate. ${ }^{70}$ Ru NPs are also active catalysts for the Sabatier reaction and for

421 Fischer-Tropsch syntheses. In this context, the presence of CO leads to the

422 elimination of surface hydrides and only CO species are adsorbed the surface of

423 the nanoparticle. ${ }^{71}$

424 These examples illustrate the multiple role that hydrogen can play, that is, as a

425 reducing agent and as a key surface species available both for stoichiometric as well

426 as for catalytic reactions. This can be advantageously exploited in catalysis, when,

427 either an easy access to the nanoparticle surface is considered as a prerequisite for

428 increased catalyst activity, ${ }^{51,52}$ or as shown recently, when the presence of specific

429 ligands on the nanoparticle surface positively impacts not only selectivity but also

430 activity. ${ }^{72,73} \mathrm{~A}$ recent review, and references therein, presents the knowledge 
431 accumulated over the years on the formation, surface chemistry and catalytic properties of Ru NPs obtained by $[\mathrm{Ru}(\mathrm{COD})(\mathrm{COT})] .^{51}$

433 Another important advantage of employing $\mathrm{H}_{2}$ as reducing agent is that it can

434 produce impurity- and oxide-free metallic NPs of easily oxidizable metals. The excellent magnetic properties of metallic magnetic NPs prepared by reduction under hydrogen are due to a surface free from oxides and other contaminating residues that could be present if another reducing agent $\left(\mathrm{CO}, \mathrm{NaBH}_{4}\right)$ was employed. For example, magnetic properties of ultrafine Co NPs prepared by $[\mathrm{Co}(\mathrm{COE})(\mathrm{COD})]$ in the presence of PVP as a stabilizing agent, present the same size dependent magnetization values as the ones of NPs of similar size ${ }^{74}$ prepared by ultrahigh vacuum techniques. Due to their small size and consequently due to the increased contribution of surface metal atoms to the magnetization value, these NPs exhibit magnetizations that exceed the bulk magnetization value of bulk Co. ${ }^{75}$ These results prove that PVP, used as stabilizing agent, does not affect the magnetic properties of the above NPs. However, this is not the case for all stabilizers. Indeed, the electronic density of the nanoparticle surface can be modified by the presence of capping agents, thus altering several chemical and physical properties among which magnetic properties. This effect is illustrated by the work of Osuna et al., who have shown that reaction at room temperature of the above-mentioned NPs with CO gives rise to a spectacular drop of their magnetization, due to the presence of $\mathrm{CO}$ on their surface. ${ }^{76}$ This ligand dependent effect on the magnetic properties has been also observed for Ni NPs prepared by reaction of $\left[\mathrm{Ni}(\mathrm{COD})_{2}\right]$ with $\mathrm{H}_{2}$ and then exposed to $\mathrm{CO}$ or $\mathrm{MeOH}$, or alternatively, prepared in the presence of hexadecylamine (HDA) or 454 trioctylphosphineoxide (TOPO). ${ }^{77}$ It was shown that among all four stabilizing agents, 455 only HDA preserves the Ni surface magnetization. 
456 Ligands do not affect the nanoparticle properties only through surface effects, as

457 they play multiple roles in nanoparticle synthesis. Ni NPs prepared by reaction of

$458\left[\mathrm{Ni}(\mathrm{COD})_{2}\right]$ with $\mathrm{H}_{2}$ in the presence of high amounts of HDA grow anisotropically. ${ }^{77}$

459 The reduction under $\mathrm{H}_{2}$ of the $[\mathrm{Co}(\mathrm{COE})(\mathrm{COD})]$ precursor in the presence of both

460 long chain amines and long chain acids as stabilizers produced for the first time

461 cobalt nanorods of hcp (hexagonal close packed) structure. ${ }^{78}$ The combination of

462 high magnetocrystalline anisotropy and the anisotropic growth along the $c$ axis of the

463 hcp structure of Co make these nano-objects well-adapted for applications for which

464 hard magnetic materials are necessary, such as magnetic recording. The ligands,

465 especially the carboxylates, are beyond any doubt decisive in the anisotropic growth

466 of these nanorods as is the presence of $\mathrm{H}_{2}$. All other parameters kept identical

467 except the presence of $\mathrm{H}_{2}$, no Co nanorods/nanowires are obtained by the

468 organometallic method. ${ }^{78,79}$ It is likely that $\mathrm{H}_{2}$ displaces the long-chain amine, which

469 transiently passivates the $\{0001\}$ facets of hcp seeds, thus allowing deposition of Co

470 atoms on these facets and anisotropic growth. ${ }^{80} \mathrm{~A}$ similar "cleaning" effect of $\mathrm{H}_{2}$ that

471 facilitates coalescence through temporary amine ligand removal from the surface of

472 NPs has been invoked in the formation of $\mathrm{Pt},{ }^{4} \mathrm{Ru},{ }^{53}$ and $\mathrm{Pd}^{43}$ anisotropically shaped

473 NPs.

474 Therefore, and despite the tedious synthesis of organometallic compounds and their

475 low stability which often requires specific handling precautions, the combination of

476 this class of precursors with $\mathrm{H}_{2}$ facilitates surface studies. It also offers the

477 opportunity to adapt the NP surface chemistry to meet the prerequisites of

478 technological domains spanning from catalysis to microelectronics, introducing the

479 appropriate stabilizing agent for each application. 
480 When in addition to, or instead of the non-coordinating hydrocarbons the precursor

481 contains ligands that have considerable coordinating ability (halogens, carbonyls,

482 amide, amidinate, carboxylate compounds) their involvement in the stabilization of

483 the NP surface, but also in the NP formation steps has to be considered.

\subsubsection{Metal-organic compounds}

Metal alkylamides $\mathrm{M}\left(\mathrm{NR}_{2}\right)_{n}$ and silylamides $\mathrm{M}\left[\mathrm{N}\left(\mathrm{SiMe}_{3}\right)_{2}\right]_{n}$ have started to be used

relatively recently for the synthesis of metal NPs. ${ }^{81-83}$ They share common characteristics with organometallic compounds, containing olefinic ligands in the sense that they are easy to be reduced at low temperature. However, while in the presence of $\mathrm{H}_{2}$, the olefinic ligands are hydrogenated and cannot act as stabilizers: the amide can be converted to hexamethyldisilazane, which can stabilize small Nps as shown in the work of Margeat et al., in which $\left\{\mathrm{Fe}\left[\mathrm{N}\left(\mathrm{SiMe}_{3}\right)_{2}\right]_{2}\right\}_{2}$ heated under $\mathrm{H}_{2}$ at $110^{\circ} \mathrm{C}$ in toluene gave rise to purely metallic iron NPs that could be isolated. ${ }^{84}$ In the presence of mixtures of long chain amines and acids, $\left\{\mathrm{Fe}\left[\mathrm{N}\left(\mathrm{SiMe}_{3}\right)_{2}\right]_{2}\right\}_{2}$ and $\left\{\mathrm{Co}\left[\mathrm{N}\left(\mathrm{SiMe}_{3}\right)_{2}\right]_{2} \mathrm{THF}\right\}$ have been decomposed giving rise to oxide-free shape controlled $\mathrm{Fe}^{81,85}$ and $\mathrm{Co}^{80,86} \mathrm{NPs}$ as well as Co-Fe dumbbells ${ }^{87}$ or FeCo alloys, ${ }^{88}$ depending on the reaction conditions. All nanoparticles display excellent magnetic properties thanks to the absence of surface oxides on their surface. When silylamide precursors are used in the presence of amine and acid stabilizers, the formation of

500 Fe and Co carboxylates is of pivotal importance, since thanks to their stability they constitute a metal reservoir that contributes mainly to the slow growth of seeds formed by less stable amine rich species. It must be noted that care has to be taken when mixing $\left\{\mathrm{Fe}\left[\mathrm{N}\left(\mathrm{SiMe}_{3}\right)_{2}\right]_{2}\right\}_{2}$ and $\left\{\mathrm{Co}\left[\mathrm{N}\left(\mathrm{SiMe}_{3}\right)_{2}\right]_{2} \mathrm{THF}\right\}$ with long chain acids, since

504 the formation of metal carboxylates is in competition with the formation of a silyl ester 
505 by reaction of the acid stabilizer with the native ligand. This was demonstrated to

506 have an impressive impact on the size and the morphology of the resulting NPs. ${ }^{88}$

507 Acetates and long chain carboxylates are easily accessible starting materials,

508 however their increased stability toward reduction by $\mathrm{H}_{2}$ requires higher reaction

509 temperatures than organometallic compounds. Despite the fact that they are rarely

510 used as starting precursors, ${ }^{89,90}$ carboxylates are often formed in situ due to the use

511 of carboxylic acids as stabilizing agents, starting from precursors of various types.

512 Due to their stability they mainly participate to the growth step of seeds. In this

513 context, under reaction conditions that do not allow reduction of $\mathrm{Co}(\mathrm{LA})_{2}(\mathrm{LA}=$

514 laurate) by $\mathrm{H}_{2}$, the addition of hexadecylamine allows the formation of cobalt

515 multipods. This could be due to the possibility of heterolytic activation of $\mathrm{H}_{2}$ through

516 coordination to the Lewis acidic species and deprotonation by the amine. ${ }^{86}$

517 In a recent work concerning Ni branched nanostructures obtained by $\left[\mathrm{Ni}\left(\mathrm{CH}_{3} \mathrm{COO}\right)_{2}\right]$

518 in the presence of oleylamine, and combining theoretical and experimental results it

519 was proposed that in the absence of $\mathrm{H}_{2}$ the growth is controlled mainly by

520 thermodynamics. Thus, the NPs are ill-defined polyhedra enclosed by $\{111\}$ and

$521\{100\}$ facets. Under a 6 bar hydrogen pressure, the obtained octopods result from a seed exposing mainly $\{100\}$ facets through a three steps growth, which is governed both by kinetics and thermodynamics. At a short time, a kinetically controlled

524 preferential orientation along the $<111>$ direction forms octapods. Upon consumption

525 of the precursors with time, the synthetic process falls into the thermodynamic 526 regime, in which the growth along the $<110>$ direction becomes dominant. Under 14

527 bar of $\mathrm{H}_{2}$ pressure, and starting from a seed that exposes mainly $\{110\}$ facets, the

528 slower Ni surface diffusion rate combined to the faster deposition rate makes the 529 synthetic process fall in the kinetically controlled regime. In this case, the high 
surface energy facet of $\mathrm{Ni}(111)$ grows more quickly (Figure 4). The influence of the

531 adsorption of the oleylamine ligand and of the solvent (ethanol) on the synthesis

532 process of Ni nanocrystals was found to be negligible according to the corresponding

533 adsorption energies, but the possible influence of carboxylates coming from the

534 precursor $\mathrm{Ni}\left(\mathrm{CH}_{3} \mathrm{COO}\right)_{2}$ has not been considered. ${ }^{91}$ In a subsequent work combining

535 modelling and experiments from the same group, the $\mathrm{H}_{2}$-induced increase of the

536 reduction rate of the Ni precursor has been also considered. It was proposed that

537 this increase also favored the overgrowth on Ni nuclei toward branched

538 nanostructures. ${ }^{92}$

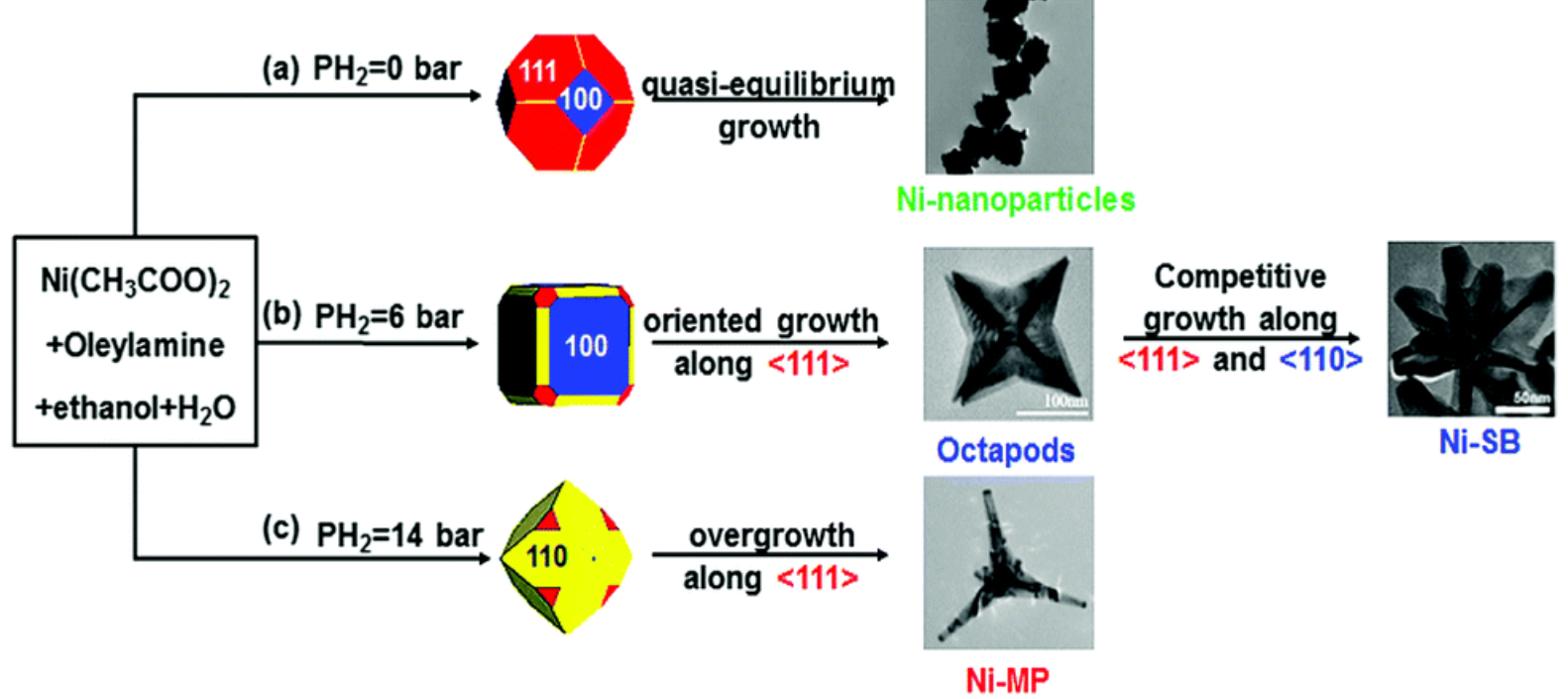

540 Figure 4. Outline of the $\mathrm{H}_{2}$ pressure influence on the formation of branched Ni nano-

objects. Reproduced from ref. 91 with permission from the PCCP Owner

544 The most popular coordination compounds used as precursors for monometallic and

545 bimetallic NPs are metal acetylacetonates. Below we present some examples where

$546 \mathrm{H}_{2}$ has been identified as a factor that contributed to the shape-controlled synthesis. 
547 In several cases however, its exact role as a structure directing agent remains rather

548 unclear.

549 In a work of Tilley and co-workers $\mathrm{Ni}$ nanocube formation from [Ni(acac $\left.)_{2}\right]$ in the

550 presence of hexadecylamine and trioctylphosphine oxide has been tentatively

551 attributed to the thermodynamic stabilization of $\mathrm{Ni}\{100\}$ facets favored by $\mathrm{H}_{2} \cdot{ }^{93}$ In

552 another study by the same group, the increase in the $\mathrm{H}_{2}$ pressure from 1 bar to 3 bar

553 results in a phase transformation of Ni from fcc (face centered cubic) to hcp, which

554 leads to anisotropic growth of arms on a fcc Ni or Au seed, ${ }^{94}$ or hcp Ni branches on

555 Au fcc seeds. ${ }^{95}$

556 Pt-based NPs of complex shapes are among the most desirable nanostructures

557 especially for electrocatalysis and a great effort is devoted for developing catalysts

558 that optimize Pt atom efficiency. ${ }^{96}$ In this context dendritic nanocubes have been

559 obtained when $\left[\mathrm{Pt}(\mathrm{acac})_{2}\right]$ was heated at $90^{\circ} \mathrm{C}$ in pure oleylamine, under 1 bar

560 hydrogen atmosphere. ${ }^{97}$ Interestingly, the oleylamine (solvent and stabilizing agent)

561 was converted to octadecylamine during the formation of the Pt nano-objects. More

562 precisely the whole amount of oleylamine was hydrogenated in $24 \mathrm{~h}$. In the absence

563 of $\mathrm{H}_{2}$, ill-defined nano-objects are obtained. The dendritic nanocubes are similar with

564 some of the nano-objects obtained from Lacroix et al. with $\mathrm{H}_{2} \mathrm{PtCl}_{6}$ in oleylamine

565 under 3 bar $\mathrm{H}_{2}$ at $150{ }^{\circ} \mathrm{C} .{ }^{31}$

566 Mao et al. using $\left[\mathrm{Pt}(\mathrm{acac})_{2}\right],\left[\mathrm{Mo}(\mathrm{CO})_{6}\right]$, and $\left[\mathrm{Ni}(\mathrm{acac})_{2}\right]$ in the presence of oleylamine

567 under $180{ }^{\circ} \mathrm{C}$ synthesized PtMoNi ultrathin nanowires. ${ }^{98}$ The authors did not succeed

568 in synthesizing the nanowires in the absence of $\mathrm{H}_{2}$, and they propose that Pt rich

569 nanowires are formed in a first step thanks to hydrogen that functions both as a

570 structure directing agent and as a mild reductant for $\mathrm{Pt}^{2+}$. The $\mathrm{Pt}$ surface assists the

571 subsequent reduction of the harder to reduce $\mathrm{Ni}^{2+}$. 
572 In situ hydrogen production resulting from other reductants $\left(\mathrm{NaBH}_{4}\right.$, hydrazine,

573 polyols) is also probably involved in determining nanocrystal shape. Interestingly, in

574 the formation of Co nanorods by the polyol method, using 1,2 butanediol as a

575 reducing agent, the secondary alcohol function of the polyol was shown to be

576 selectively oxidized to a ketone with the concomitant formation of molecular

577 hydrogen (transfer hydrogenation reaction). It is thus likely that the in situ produced

$578 \mathrm{H}_{2}$ contributes to the Co shape control. ${ }^{99}$

579 Homoleptic metal carbonyls have been extensively used for the preparation of metal

580 NPs, but rarely employed with $\mathrm{H}_{2}$ since the metal centers being already reduced, no

581 reducing agent is needed. However, in an example that illustrates the parallel

582 catalytic reactions that can take place with $\mathrm{H}_{2}$ and $\mathrm{CO}$, Ru nanostars and

583 nanourchins have been prepared by thermolysis of $\left[\mathrm{Ru}_{3}(\mathrm{CO})_{12}\right]$ under $\mathrm{H}_{2}$ in the

584 presence of hexadecylamine and palmitic acid. ${ }^{58}$ The gas analysis at the end of the

585 synthesis revealed the presence of methylcyclohexane resulting from the

586 hydrogenation of the toluene solvent, as well as that of linear alkanes, which were

587 most likely formed by the activity of the Ru NPs as a Fischer-Tropsch catalyst.

588 In conclusion, the examples presented in this part show that apart from reducing the

589 precursors in which the metal center is not in the zero-oxidation state, $\mathrm{H}_{2}$ can reduce

590 native ligands, stabilizing agents as well as organic substrates and even solvents,

591 either when coordinated to a soluble compound or when chemisorbed on a metal

592 nanoparticle. Last but not least, dihydrogen can be a shape directing agent through

593 modulation of the nucleation and growth steps and facet selective passivation

594 (Scheme 3). 


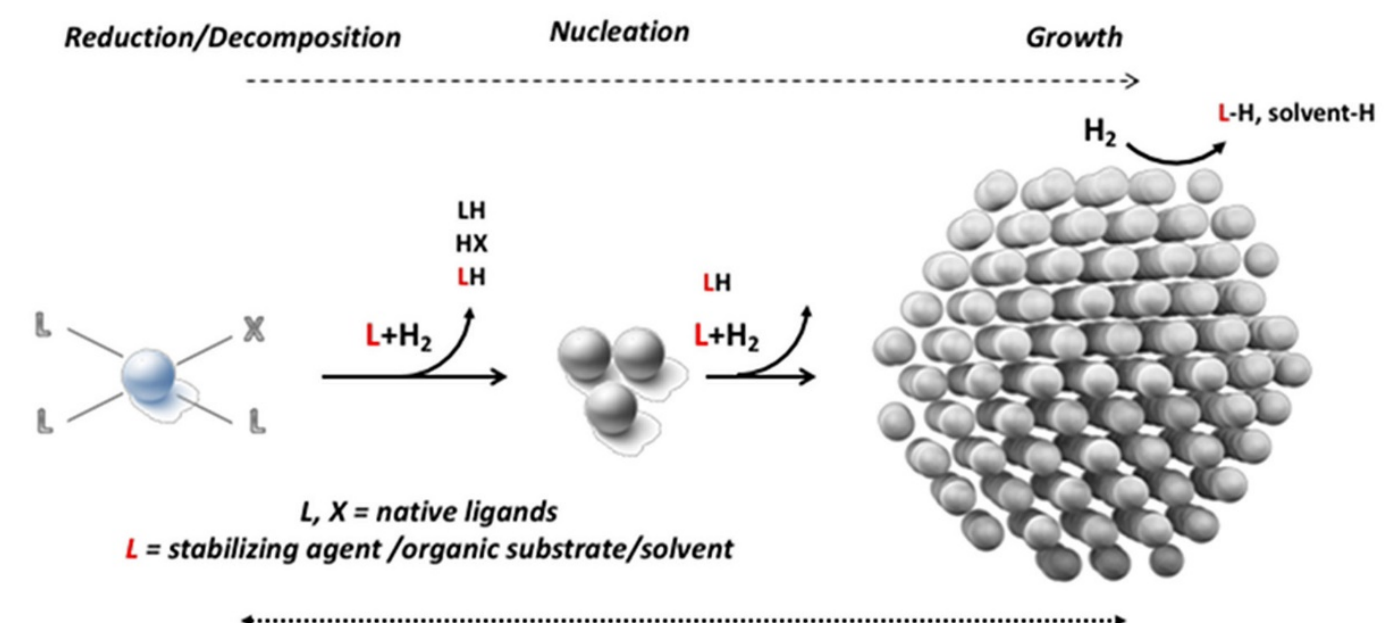

Hydrogenation

Precursor decomposition, ligand, solvent, organic compound hydrogenation

Shape directing agent

597 Scheme 3. Different roles of $\mathrm{H}_{2}$ throughout all the steps of the NPs formation process.

\section{Carbon monoxide}

601

602 The reducing strength of $\mathrm{CO}$ is comparable to that of $\mathrm{H}_{2},{ }^{100}$ but it can also form metal

603 NPs without reducing the metal center, as for instance by displacing at room

604 temperature labile ligands from organometallic precursors in which the metal center 605 is in the zero oxidation state. CO has been used in the synthesis of metal and metal 606 alloy NPs, either by direct gas admission, or alternatively, through the decomposition

607 of metal carbonyl complexes. Its usual oxidation product $\left(\mathrm{CO}_{2}\right)$ is inert and easily 608 eliminated from the reaction medium. Apart from being a reducing agent, the CO 609 molecule is one of the most important ligands in transition metal chemistry. Thanks

610 to its ability to both donate and accept electrons from transition metals, it plays a 611 prominent role in the design of catalysts used in many carbonylation reactions. CO 
612 reacts with metal centers in low oxidation state to form metal carbonyls, whereas

613 interaction with metal centers in high oxidation state needs previous reduction and is

614 weak. ${ }^{101}$ In addition, CO can interact strongly with metal surfaces, with chemisorption

615 behavior that differs not only from one metal to another but also from one

616 crystallographic surface to the other for the same metal. ${ }^{102}$ Thus, it can behave as

617 strong shape directing agent as illustrated from the numerous examples in the

618 literature where shape control is attributed, at least in part, to CO. ${ }^{103}$ Once CO

619 reduction or ligand displacement has formed the first solid entities, additional CO

620 reactions on the metal surface can be operational. Numerous studies on

621 heterogeneous catalysis have demonstrated that, depending on the nature of the

622 metals and the temperature of the reaction, $\mathrm{CO}$ chemisorption can be either

623 molecular or dissociative. Transition metals such as $\mathrm{Fe}, \mathrm{Co}$, or $\mathrm{Ni}$ favor $\mathrm{CO}$

624 dissociation while adsorption on noble transition elements is non-

625 dissociative. ${ }^{102,104,105}$ Therefore, depending on the metal and the reaction conditions

626 (temperature, presence of other gases among which $\mathrm{H}_{2}$ ) the metal NPs can be very

627 different in nature (reduced metals or metal carbides) or have a very different surface

628 state (CO passivated or not), with important consequences on their physical and

629 chemical properties. Below, we present some non-exhaustive examples, which give

630 an overview of the rich chemistry associated to the use of $\mathrm{CO}$ in nanoparticle

631 synthesis.

632

633 3.1. Ligand displacement without reduction

$634 \mathrm{CO}$ has been extensively used in the synthesis of Pd and Pt metal NPs starting from

635 the zero-valent organometallic precursors $\left(\left[\mathrm{Pd}_{2}(\mathrm{dba})_{3}\right]\right.$ and $\left.\left[\mathrm{Pt}(\mathrm{dba})_{\mathrm{x}}\right]\right)$, through

636 displacement of these ligands. ${ }^{40,106,107}$ Since NPs are formed at low temperature, the 
$637 \mathrm{CO}$ is adsorbed intact on the nanoparticle surface at the end of the reaction. Due to

638 its surface dependent and multimodal adsorption on metal surfaces, it is a

639 particularly useful molecule for probing the surface of metal particles. Stretching

640 vibrations of the $\mathrm{C} \equiv \mathrm{O}$ bond appear in the IR spectrum between 2200 and $1700 \mathrm{~cm}^{-1}$

641 and the CO binding mode (atop, bridging, hollow) can be identified by the position of

642 the signals. ${ }^{40,108}$ Solid state ${ }^{13} \mathrm{C}$ NMR techniques developed for probing

643 heterogeneous catalyst surfaces ${ }^{109}$ have been very successfully applied to the

644 domain of colloidal NPs in studies concerning both surface state and

645 reactivity. ${ }^{72,107,110-112}$ On the other hand, $\mathrm{CO}$ can persist on the final nanoparticle

646 surface and it may affect their physical, ${ }^{75,79}$ and chemical properties. These latter can

647 be severely impacted since $\mathrm{CO}$ acts as a poison of active sites in many catalytic

648 reactions. ${ }^{113}$

\section{$650 \quad 3.2$ Mild reducing agent for reaction monitoring}

651 There are only few examples in the literature of studies that propose reaction

652 pathways where reduction by $\mathrm{CO}$ gives rise to metal NPs. The slow reduction

653 kinetics by $\mathrm{CO}$ compared to $\mathrm{NaBH}_{4}$, enabled the $\mathrm{CO}$ induced synthesis of thiolate

654 protected Au nanoclusters $\mathrm{Au}_{25}(\mathrm{cys})_{18}$ (cys = cysteine) to be followed. The clusters

655 were prepared from $\mathrm{HAuCl}_{4}$ and cysteine in aqueous basic solution $(\mathrm{pH}=11)$ at

656 room temperature. ${ }^{114} \mathrm{CO}$ interaction with the $\mathrm{Au}(\mathrm{III})$ metal center is not favored.

657 Despite the fact that cysteine is a milder reducing agent than $\mathrm{CO}$, it can perform the

658 first reduction from $\mathrm{Au}(\mathrm{III})$ to a $\mathrm{Au}(\mathrm{l})$-thiolate complex. $\mathrm{CO}$ can then perform the

659 second reduction step. The slow reduction by $\mathrm{CO}$ allowed monitoring of the

$660 \mathrm{Au}_{25}$ (cys) ${ }_{18}$ formation process by UV-Vis and mass spectrometry, and identification

661 of several key intermediates. Increasing the $\mathrm{pH}$ enhances the reduction capability of 
$662 \mathrm{CO}$. The authors observed that $\mathrm{CO}$ was not present on the surface of the

663 nanoclusters probably due to the catalytic activity of Au nanoclusters in alkaline

664 conditions for $\mathrm{CO}$ oxidation to $\mathrm{CO}_{3}{ }^{2-}$. This $\mathrm{CO}$ mediated synthesis has been

665 extended to other $A u_{n}(S R)_{m}$, nanoclusters ${ }^{115}$ and a review on this method has been

666 published. ${ }^{116}$

667

6683.3 Homogeneously catalyzed ligand carbonylation

$669 \mathrm{CO}$ is not only a reducing agent that is converted to inert $\mathrm{CO}_{2}$ during nanoparticle

670 formation. A multitude of carbonylation reactions can take place in the presence of

671 molecular metal precursors that are acting as catalysts. This is illustrated in a work in

672 which $\left[\mathrm{Pt}\left(\mathrm{CH}_{3}\right)_{2}(\mathrm{COD})\right]$ was reduced by $\mathrm{CO}$ at atmospheric pressure in the presence

673 of hexadecylamine (HDA) and oleic acid. CO, rapidly substitutes COD leading to the

674 formation of [cis-Pt $\left.\left(\mathrm{CH}_{3}\right)_{2}(\mathrm{CO})(\mathrm{HDA})\right]$ and [cis- $\left.\mathrm{Pt}\left(\mathrm{CH}_{3}\right)_{2}(\mathrm{CO})_{2}\right]$ which were identified

675 by ${ }^{1} \mathrm{H}$ and ${ }^{13} \mathrm{C}$ NMR. Upon heating at $110{ }^{\circ} \mathrm{C}$ under $\mathrm{CO}$, complete decomposition of

676 the molecular Pt compounds occurs, giving rise to $\mathrm{Pt}(0)$ NPs stabilized by a mixture

677 of N,N'-bis(hexadecyl)urea and CO ligands as shown by IR and ${ }^{13} \mathrm{C}$ NMR studies. In

678 addition, NMR analysis of the supernatant at the end of the reaction evidenced the

679 formation of a secondary amide identified as $\mathrm{N}$-(hexadecyl)acetamide, $\mathrm{CH}_{3} \mathrm{CONHR}$,

680 and a small amount of N,N'-bis(hexadecyl)urea. These results indicate that HDA

681 carbonylation has taken place. ${ }^{117}$ The decomposition outline that is proposed to

682 account for the carbamide formation through [cis- $\left.\mathrm{Pt}\left(\mathrm{CH}_{3}\right)_{2}(\mathrm{CO})(\mathrm{HDA})\right]$ is shown in

683 Scheme 4. This work evidences the complexity of the reactions taking place during

684 nanoparticle synthesis.

685

686 


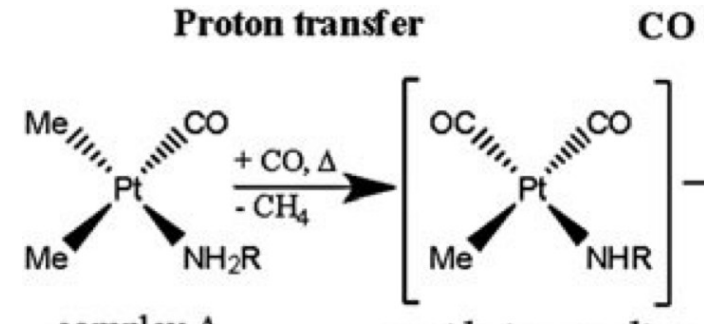

complex A

amido interme diate
CO insertion

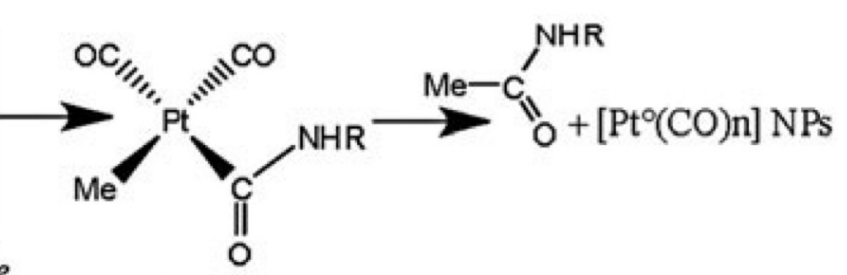

carbamido intermediate

689 Scheme 4. Outline of the proposed reactions taking place on the Pt center during the

690 formation of Pt nanoparticles. Reproduced from ref. 117 with permission from

\section{The Royal Society of Chemistry Copyright 2010}

692

693 Similar reactivity was demonstrated when Au NPs were obtained from the reduction 694 under $\mathrm{CO}$ of $\mathrm{AuCl}\left(\mathrm{NH}_{2} \mathrm{R}\right)$ complexes formed in situ from $\mathrm{AuCl}(\mathrm{THT})(\mathrm{THT}=$ 695 tetrahydothiophene). While $\mathrm{H}_{2}$ fails to yield size and shape controlled $\mathrm{Au}$ NPs under all the conditions employed, the use of long chain amines (dodecylamine or

697 hexadecylamine) as stabilizing agent in THF at $70^{\circ} \mathrm{C}$ in the presence of $\mathrm{CO}(1 \mathrm{bar})$

698 leads to stable and well-defined Au NPs of about $7 \mathrm{~nm}$ and with a narrow size

699 distribution. Solid-state ${ }^{13} \mathrm{C}$ MAS NMR and liquid state ${ }^{1} \mathrm{H}$ NMR studies

700 demonstrated the presence of a carbamide (RNHCONHR) species resulting from the carbonylation of the amine on the Au NPs. The authors noted that this unexpected reaction has a positive effect on the NP stability. ${ }^{118}$

\subsection{CO as shape directing agent}

As already mentioned, several physical and chemical properties depend on the nanoparticle shape. A consequence stemming from $\mathrm{CO}$ affinity for metal surfaces is that it can act as a shape directing agent by selectively passivating certain nanocrystal facets during growth. The interest in metal nanocrystal synthesis is 
709 largely associated to the optimization of their catalytic properties. Considering that

710 the performances of catalysts are dependent on the type and number of exposed

711 facets, tailoring of metal nanocrystal morphology is currently a very active area of

712 research. ${ }^{119}$ Since Pt- and Pd-based catalysts are among the most widely applied in

713 thermal catalysis as well as in electrocatalysis, an intense research activity concerns

714 the control of their shape. Furthermore, CO assisted growth of Pt and Pd shape-

715 controlled NPs has paved the way to the development of this method for their

716 alloys, ${ }^{2,120-122}$ as well as for other metals. ${ }^{103,123}$ In most of these cases, metal and

717 facet depending adsorption of $\mathrm{CO}$ during nanocrystal formation is claimed to be one

718 of the crucial parameters for shape control.

719 Metal carbonyls such as $\mathrm{Fe}(\mathrm{CO})_{5},{ }^{124} \mathrm{Co}_{2}(\mathrm{CO})_{8},{ }^{125}$ and $\mathrm{W}(\mathrm{CO})_{6}{ }^{126}$ have been

720 demonstrated to play a decisive role in the formation of shape controlled NPs,

721 especially in the case of cubic Pt and shape controlled Pt-based alloys. ${ }^{127}$ In some

722 works the possible role of $\mathrm{CO}$ from the decomposition of the metal carbonyls has

723 been ignored and the morphology has been attributed to the reducing capability of

724 the zero valent metal of the carbonyl complex, which assisted the reduction of $\mathrm{Pt}(\mathrm{II})$

725 and regulated the nucleation process. However, other works have demonstrated that

726 the presence of $\mathrm{CO}$ alone is enough to induce the formation of specific morphologies

727 depending on the nature of the NPs. ${ }^{128}$ Compared to metal carbonyls, the use of CO

728 has the advantage that it does not introduce any metal impurities, that could be

729 finally found in the target nanocrystals. Thus, C.B. Murray et al., have reported the

730 rapid formation of monodisperse $\mathrm{Pt}$ nanocubes from $\left[\mathrm{Pt}(\mathrm{acac})_{2}\right]$ in the presence of

731 oleylamine and oleic acid, $\mathrm{Pd}$ spherical nanoparticles from $\left[\mathrm{Pd}(\operatorname{acac})_{2}\right]$ in the

732 presence of oleylamine, oleic acid and TOP (trioctylphosphine), and ultrathin Au

733 nanowires from $\mathrm{AuCl}$ in the presence of oleylamine, when $\mathrm{CO}$ was bubbled through 
734 their solutions in organic media. ${ }^{128}$ The absence of $\mathrm{CO}$ bands in the IR spectra

735 obtained from the Pt nanocrystals and a control experiment after having evacuated

736 bubbled $\mathrm{CO}$ before heating, led the authors to the conclusion that $\mathrm{CO}$ was acting as

737 reductant and not as a capping agent, and that the observed shapes were not

738 formed due to the formation of a CO containing precursor. The authors assigned the

739 nano-object shape to the fast reduction kinetics induced by $\mathrm{CO}$.

740 However, Wu et al. correlated the cubic shape of Pt NPs with the preferential binding

741 of $\mathrm{CO}$ on $\{100\}$ facets. Pt nanoparticles prepared from $\left[\mathrm{Pt}(\mathrm{acac})_{2}\right]$ at $180^{\circ} \mathrm{C}$ in the

742 presence of oleylamine and oleic acid under $\mathrm{CO}$ adopt a cubic shape. More

743 precisely, it was shown that while both amine and CO were necessary for the

744 formation of cubic nanostructures, the presence of oleic acid was not necessary

745 (Figure 5 ). ${ }^{129}$ Their results were supported by IR analyses, which confirmed the

746 presence of $\mathrm{CO}$ and oleylamine on the nanocube surface, and periodic DFT

747 calculations that showed that the $\mathrm{Pt}(100)$ surface can be significantly stabilized by

748 the co-adsorption of $\mathrm{CO}$ and oleylamine.
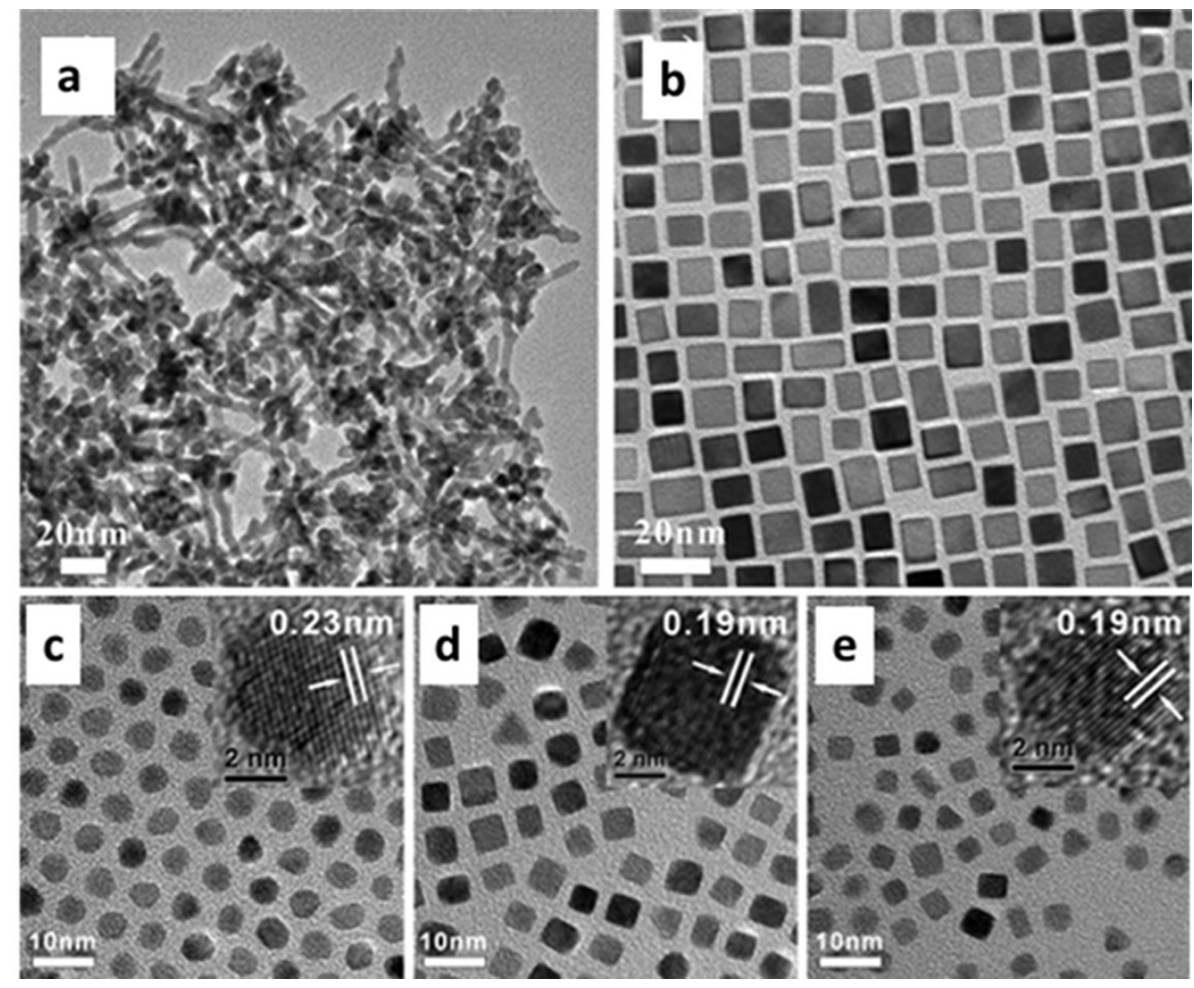
750 Figure 5. TEM images of (a) Pt nanodendrites synthesized without CO; (b) $10.3 \mathrm{~nm}$

751 Pt nanocubes prepared under CO flow at $180^{\circ} \mathrm{C}$, both using $4: 1$ oleylamine/oleic

752 acid; (c) spherical NPs in pure oleylamine under CO flow; (d) in pure oleylamine

753 under $1 \mathrm{~atm} \mathrm{CO}$ and (e) under $2 \mathrm{~atm} \mathrm{CO}$. The insets are the corresponding HRTEM

754 images. Adapted from ref. 129 with permission from The Royal Society of

755 Chemistry Copyright 2011

756

757 In that case oleic acid did not seem to be essential for obtaining the cubic NPs since even in its absence, the cubic shape was obtained by $\mathrm{CO}$ and oleylamine. However, very recently, oleic acid was shown to be a decisive actor allowing Pt cubes and bars

760 to be obtained when using the same as above precursor [ $\left.\mathrm{Pt}(\mathrm{acac})_{2}\right]$, which was dissolved in oleic acid and heated at $80^{\circ} \mathrm{C}$. The authors propose that this step leads to $\left[\mathrm{Pt}_{3}(\text { oleate })_{6}\right]$. Subsequent increase of the temperature to $120^{\circ} \mathrm{C}$ leads to oleic acid catalytic decarbonylation, presumably from [ $\left.\mathrm{Pt}_{3}(\text { oleate) })_{6}\right]$, which was proposed as a $\mathrm{Pt}(\mathrm{II})$ intermediate. The authors claim that the $\mathrm{CO}$ produced by this step acted as a reducing agent to provide $\mathrm{Pt}(0)$ atoms, and as a capping agent stabilizing $\{100\}$ type facets of the nanoparticles. ${ }^{130}$ The authors mention the different catalytic reactions likely to take place on the Pt surface.

Under the light of these recent results, one may wonder why decarbonylation of the oleic acid did not take place under the very similar (even harsher) reaction conditions employed in the work of Wu et al. ${ }^{129}$ Indeed, in that work, there was no indication of $\mathrm{CO}$ production. It is therefore likely that other catalytic reactions are favored under those conditions. Several shape-controlled Pt-based alloys with a great variety of metals have been synthesized since the first Pt nanocubes formed through the $\mathrm{CO}$ reduction by $\left[\mathrm{Pt}(\mathrm{acac})_{2}\right]^{126,127,131}$ 
775 Wu et al. proposed that preferential binding of $\mathrm{CO}$ on the $\{100\}$ facets could also

776 favor addition of metal atoms onto specific facets of Pt alloy nanocrystals, because

$777 \mathrm{CO}$ can undergo preferential oxidation to $\mathrm{CO}_{2}$ on selected surfaces. ${ }^{127}$ Nevertheless,

778 based on several works on the synthesis of $\mathrm{Pt}_{3} \mathrm{M}$ nanoparticles $(\mathrm{M}=\mathrm{Fe}, \mathrm{Ni}, \mathrm{Co})$, it

779 seems that the presence of $\mathrm{CO}$ alone is not enough, and several conditions have to

780 be met (temperature ramp, stabilizing agents, etc.) to guarantee stoichiometry and

781 shape selectivity of the resulting NPs. ${ }^{126,127,131}$

782 In contrast to what is observed on $\mathrm{Pt}$, CO binds preferentially on $\mathrm{Pd}\{111\}$ facets. As

783 a result, Pd NPs adopt shapes that expose $\{111\}$ facets such as ultrathin nanoplates

784 and nanosheets. Nowadays, one of the preferred methods for the synthesis of 2D

785 ultrathin NPs of many metals is based on the so-called CO "confined growth" in

786 solution which designates the characteristic limitation of the 2D nano-objects

787 thickness to a few atomic layers, by selective adsorption of the $\mathrm{CO}$ on the highly

788 exposed $\{111\}$ basal facets of the $2 \mathrm{D} \mathrm{Pd}$ based nano-objects. ${ }^{132}$

789 In an early work Schlotterbeck et al. obtained, "somewhat surprisingly" as they

790 stated, hexagonal platelets with a relatively narrow size distribution through reduction

791 of $\left[\mathrm{Pd}(\mathrm{OAc})_{2}\right]$ by $\mathrm{CO}$ at room temperature, in toluene solutions of amphiphilic

792 polymers. In comparison, reduction with $\mathrm{H}_{2}$ or $\mathrm{LiBEt}_{3} \mathrm{H}$ afforded spherical palladium

793 NPs. Although an interpretation of this result was not straightforward, the authors

794 note that the reduction is much slower with $\mathrm{CO}$ than with the other reducing agents

795 and that unstable $\mathrm{Pd}(\mathrm{II})$ carbonyl compounds are intermediate species. ${ }^{133}$

796 Remita et al. synthesized ultrathin hexagonal Pd nanosheets in a water/toluene

797 mixture purged with $\mathrm{CO}$ gas ${ }^{134}$ from precursors in which Pd was in different formal

798 oxidation states. A 2D morphology was obtained in all cases, except in the case of

$799\left[\mathrm{Pd}_{2}(\mathrm{dba})_{3}\right]$, which reacted very fast with $\mathrm{CO}$. The authors have assigned the 
800 formation of the 2D Pd nano-objects to the slow kinetics of nucleation and growth

801 when less reactive precursors were employed.

802 Zheng et al., ${ }^{135}$ employed the $\mathrm{CO}$ mediated growth of Pd ultrathin nanosheets with

803 original optical and excellent electrocatalytic properties (Figure 6).

804

805

806

807

808

809

$810\left[\mathrm{Pd}(\mathrm{acac})_{2}\right]$ was reduced at low temperatures (r.t. to $\left.100^{\circ} \mathrm{C}\right)$ in the presence of PVP

Figure 6. TEM images of (a) Pd nanosheets, inset: photograph of a dispersion of the nanosheets in ethanol; (b) an assembly of Pd nanosheets perpendicular to the TEM grid, and their thickness distribution. Adapted from ref. 135 with permission from

\section{Springer Nature Copyright 2011.}

\section{a}

\section{$100 \mathrm{~nm}$}

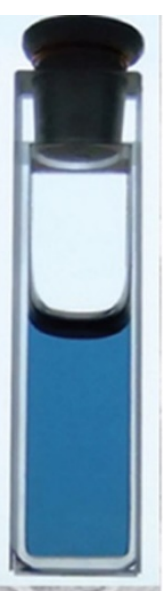

b

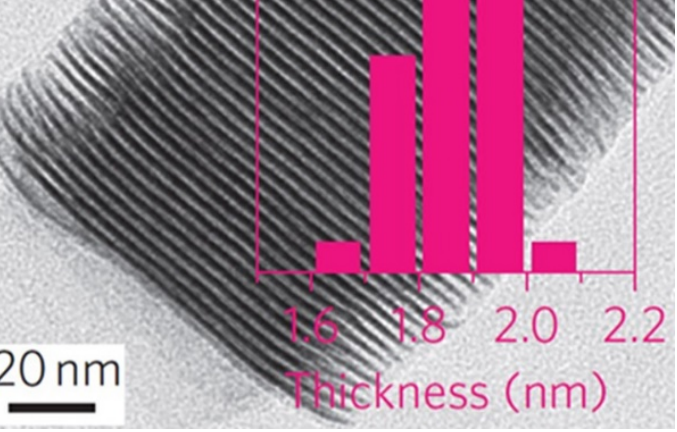
and ammonium halides in various organic solvents. Pd nanosheets of different sizes and excellent size distribution was achieved by adjusting the reaction conditions.

813 Electrochemical CO stripping has revealed that $96 \%$ of the exposed nanosheet

814 surface were $\operatorname{Pd}(111)$. The authors assigned the shape to the strong adsorption of

$815 \mathrm{CO}$ on the $\{111\}$ facets of the sheets, preventing growth along the $<111>$ direction.

816 Less efficient halide adsorption on the six halide-bound $\{100\}$ facets allowed lateral

817 growth. In a subsequent work by the same group, the anionic intermediate $\left[\operatorname{Pd}_{2}(\mu-\right.$ 
$\left.818 \mathrm{CO})_{2} \mathrm{Cl}_{4}\right]^{2-}$ was prepared by reaction of $\mathrm{H}_{2} \mathrm{PdCl}_{4}$ with $\mathrm{CO}$. Ultrathin $\mathrm{Pd}$ nanosheets

819 exposing $\{111\}$ facets were obtained by simply adding water to a solution in DMF

820 (DMF= dimethylformamide) of the intermediate $\left[\mathrm{Pd}_{2}(\mu-\mathrm{CO})_{2} \mathrm{Cl}_{4}\right]^{2-}$, in the absence of

821 any organic capping agents. Control experiments have demonstrated that the CO

822 ligands in $\left[\mathrm{Pd}_{2}(\mu-\mathrm{CO})_{2} \mathrm{Cl}_{4}\right]^{2-}$ reduce $\mathrm{Pd}(\mathrm{I})$ with concomitant $\mathrm{CO}$ oxidation to $\mathrm{CO}_{2}$, and

823 serve as capping agents for the formation of $\mathrm{Pd}$ nanosheets. The palladium

824 nanosheets produced by this method did not contain any organic capping agent on

825 their surface and exhibited improved catalytic and electrocatalytic properties compared to polymer capped Pd nanosheets. ${ }^{136}$ In a recent work, Yang et al. suggested that $\left[\mathrm{Pd}(\mathrm{acac})_{2}\right]$ reacted with acetic acid under $\mathrm{CO}$ to form a $\left[\mathrm{Pd}_{4}(\mathrm{CO})_{4}(\mathrm{OAc})_{4}\right]$ intermediate, which adsorbs onto $\mathrm{Pd}\{110\}$ facets, directly leading to anisotropic growth along the $<011>$ directions and the formation of hexagonal $2 \mathrm{D}$

830 Pd nano-objects. ${ }^{137}$

831 Interestingly, in a system that under $\mathrm{CO}$ gives rise to $\mathrm{Pd}$ nanosheets, and under $\mathrm{H}_{2}$

832 forms $\mathrm{Pd}$ nanoaggregates, when both $\mathrm{CO}$ and $\mathrm{H}_{2}\left(\mathrm{CO}: \mathrm{H}_{2}=1: 4\right)$ are introduced,

833 tetrahedra and tetrapods, both exposing $\{111\}$ facets, are produced (Figure 7$).{ }^{138}$

834 The formation of tetrahedra and tetrapods is attributed to the reduced CO adsorption 835 energy on $\mathrm{Pd}\{111\}$ facets due to the presence of $\mathrm{H}_{2}$. Based on experimental data and DFT calculations, the authors proposed a mechanism that involves the initial

837 formation of NPs with a $\mathrm{PdH}_{\mathrm{x}}$ phase, which is converted to $\mathrm{Pd}(0)$ upon exposure to air. Thus, in pure $\mathrm{CO}$, the high $\mathrm{CO}$ coverage on $\mathrm{Pd}(111)$ prevents freshly reduced $\mathrm{Pd}$ atoms to deposit on $\{111\}$ facets explaining why ultrathin nanosheets are formed. On

840 the other hand, for $\mathrm{PdH}_{x}(111)$ surface, low $\mathrm{CO}$ coverage, allows $\mathrm{Pd}$ atoms to be directly deposited on $\mathrm{PdH}_{\mathrm{x}}(111)$ surfaces, producing the 3D morphology. 


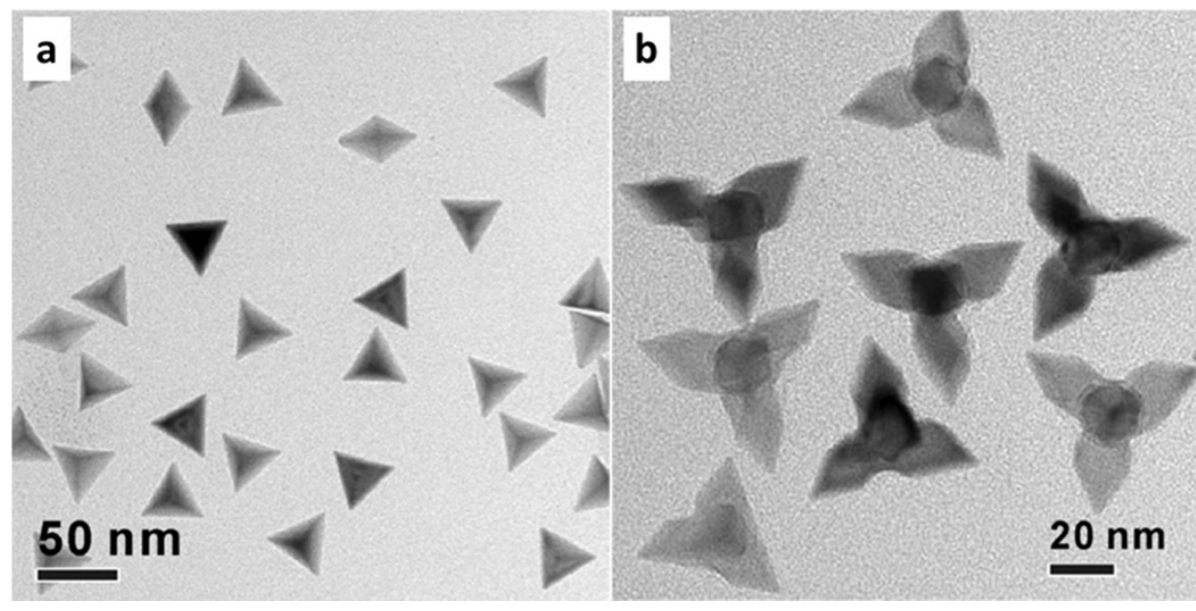

Figure 7. (a) Pd tetrahedral nanocrystals synthesized at $140{ }^{\circ} \mathrm{C}$ from $\mathrm{Pd}(\mathrm{acac})_{2}$ in the presence of PVP and under 1:4 CO/H2. (b) Pd tetrapods synthesized at $100{ }^{\circ} \mathrm{C}$ from Pd(acac) $)_{2}$ in the presence of PVP and under 1:4 CO/ $\mathrm{H}_{2}$. Adapted from ref. 138 with permission from the American Chemical Society Copyright 2012.

The simultaneous presence of $\mathrm{CO}$ and $\mathrm{H}_{2}$ introduces additional possibilities in the panel of catalytic reactions that can take place on soluble metal species (hydroformylation) as well as on the NP surface (such as carbide formation, methanation, water gas shift, Fischer-Tropsch, etc.), the latter being possible especially with early transition metals that easily dissociate $\mathrm{CO}$.

For instance, monodisperse iron carbide NPs that can be used as heating agents with high heating capacities were formed by direct reaction of $\mathrm{CO}$ and $\mathrm{H}_{2}$ at $150{ }^{\circ} \mathrm{C}$ on preformed iron (0) NPs. ${ }^{139}$ When combined with an appropriate catalyst they can magnetically activate various catalytic reactions. ${ }^{139,140}$ Considering the mild reaction conditions under which carbidization takes place, similar to the ones employed in many syntheses of metal NPs, one can wonder whether similar reactions could not

861 take place especially with early transition metals and in the presence of chemicals

862 that can produce $\mathrm{CO}$ in situ. One example is described in the work of Meffre et al., in 
863 which iron carbide NPs were produced by the reaction of $\mathrm{Fe}(\mathrm{CO})_{5}$ with $\mathrm{Fe}(0) \mathrm{NPs}$ at

$864150^{\circ} \mathrm{C}$ either under $\mathrm{Ar}$ or under $\mathrm{H}_{2},{ }^{141}$ In another recent work, iron carbide

865

866

867

868

869

870

871

872

873

874

875

876

877

878

880

881

882

883

884

885

886

887 nanoparticles were also produced in a continuous millifluidic system under $\mathrm{N}_{2}$ from $\mathrm{Fe}(\mathrm{CO})_{5}$ in the presence of oleylamine, albeit at higher temperatures $\left(230{ }^{\circ} \mathrm{C}\right) .{ }^{142}$

\section{Risks associated to the use of $\mathrm{H}_{2}$ and $\mathrm{CO}$ and safety related best practices}

Hydrogen is odorless and non-toxic, however, it is very flammable, requiring a small amount of energy to ignite. In fact, if leaking from a pipe at a high pressure, $\mathrm{H}_{2}$ can self-ignite without the aid of an external energy source. It can also form an explosive mixture with the oxygen of the air. It has to be noted that gaseous hydrogen cannot be detected by the human senses, and its flame is also invisible. In fact, the range of hydrogen/air mixtures that will explode is wide: mixtures containing from as little as $4 \% \mathrm{v} / \mathrm{v}$ hydrogen, which is the Lower Explosive Limit (LEL), up to as much as $75 \%$ v/v, which is the Upper Explosive Limit (UEL), may propagate a flame. Hydrogen can be explosive at concentrations of $18.3 \%-59 \% .{ }^{143}$ However, it is important to note that an explosion cannot occur in a pure $\mathrm{H}_{2}$ reservoir, since an oxidizer, such as oxygen, must be present in a concentration of at least $10 \%$ pure oxygen (or $41 \%$ air). The main risk is associated to any leaks that could fulfil the explosion/ignition conditions upon mixing with air. Therefore, hydrogen cylinders should be placed in a dedicated place outside the laboratory, connected with copper/stainless steel piping into the laboratory and secured to prevent tampering. Pipework should be regularly leakchecked to prevent large leaks of hydrogen. Fortunately, $\mathrm{H}_{2}$ generators can very successfully replace gas cylinders. They generate gas on demand, as it is required by most of the laboratory set-ups for the synthesis of NPs. This means that they only store a minimal amount of gas, not enough to reach hydrogen's LEL ( $4.1 \%$ in air). 
888 On the other hand, $\mathrm{CO}$ is also odorless, highly flammable, and, in contrast to $\mathrm{H}_{2}$

889 which is non-toxic, it is highly toxic/poisonous and lethal if inhaled in not so high

890 doses. The OSHA personal exposure limit (PEL) for CO is 50 parts per million (ppm).

891 The NIOSH recommended immediately dangerous to life and health concentration

892 (IDLH) for CO is $1,200 \mathrm{ppm}$. The IDLH is the concentration that could result in death

893 or irreversible health effects, or prevent escape from the contaminated environment

894 within 30 minutes. Carbon monoxide should be used in a fumehood and all valves,

895 connections, regulators and fittings should be checked for leaks. A carbon monoxide

896 detector should be in use while $\mathrm{CO}$ is flowing at the proximity of the experimental

897 set-up and individual portable detectors should be worn by the users.

898 It is also important to note that the small amounts of gas reactants required and the

899 relatively low pressures employed in the academic research for nanoparticle

900 synthesis limit the risks of an accident, as the conditions for fire, explosion or

901 intoxication are hardly met under adapted working conditions (appropriately installed

902 gas cylinders and connections, fumehoods, adapted pressure vessels, pressure

903 release devices).

904 To conclude, as for all chemicals, when working with $\mathrm{H}_{2}$ or $\mathrm{CO}$, it is essential to learn

905 about their physico-chemical properties in order to know their behavior and,

906 therefore, any possible associated risks. Appropriate practices have to be adopted

907 and adapted to the working conditions and safety regulations of each laboratory.

908 Prior to conducting any work with carbon monoxide, designated personnel must

909 provide training, specific to the hazards involved in working with these substances,

910 and detailed information on emergency procedures. Last but not least, safety

911 equipment should always include detection systems and alarms as second line

912 defense for possible leaks. 


\section{5. Conclusions}

$914 \mathrm{H}_{2}$ and $\mathrm{CO}$ are convenient reducing agents of intermediate strength, allowing the

915 reduction of a large variety of metals by modulation of their reducing ability through

916 the proper choice of reaction conditions. Depending on the reaction conditions they

917 let behind little or no residues. This is especially true for $\mathrm{H}_{2}$.

918 In some cases where $\mathrm{H}_{2}$ and $\mathrm{CO}$ are used for the synthesis of nanoparticles, the

919 reaction is not a not real reduction but a simple displacement of ligands from

920 precursors in which the metal center is already reduced. Reductants or not, they can

921 affect the outcome of the nanoparticle formation by various ways as exposed

922 throughout this chapter.

923 After some decades of intensive research, the "black box" of nanoparticle synthesis

924 is now starting to be less black thanks to the knowledge accumulated over the years.

925 The recent development of cutting-edge characterization techniques combined to

926 modeling have already significantly contributed, and they are expected to contribute

927 even more in the near future to a better understanding of the possible reaction

928 processes that lead to NP formation. ${ }^{144} \mathrm{H}_{2}$ and $\mathrm{CO}$ have been used with many

929 metals, under different reaction conditions and in the presence of very different

930 capping agents, some of them being able to act as reducing agents, but only very

931 few comparative studies which describe syntheses using the same reaction

932 conditions where only the reducing agent is varied are available. This lack of data

933 does not allow the evaluation of the real influence of the reducing agent on the

934 nanoparticle structural characteristics. Another point worth to be noted is that these

935 gases are most of the times used for reducing molecular metallic species in mixtures

936 where other potential reducing agents are also present, which raises the question of

937 their degree of participation in the reduction process. An answer to this question 
938 requires an identification of the oxidized products, which is very rarely part of the

939 usual investigation procedure in the domain of nanoparticle synthesis. In this

940 respect, the use of new experimental and theoretical tools could give precious

941 information. Thus, revisiting some of the most interesting examples is extremely

942 important.

943 Last but not least, "analyzing" the inherent complexity of these reactions is a crucial

944 step; however, "synthesizing" by combining the accumulated knowledge across

945 several disciplines is equally essential towards a better understanding of the

946 complex processes involved.

947 In this respect, when used as reducing agents for metal nanoparticle synthesis, $\mathrm{H}_{2}$

948 and $\mathrm{CO}$, are always supplied to the reaction medium in excess, large enough to be 949 catalytically transformed. Most of the metals, either in their molecular form or in the solid state are active catalysts for a variety of reactions involving $\mathrm{H}_{2}$ (hydrogenation),

951 CO (carbonylation), or their mixture (water gas shift reaction, Fischer-Tropsch

952 synthesis). From this point of view, the huge available knowledge on homogeneous

953 and heterogeneous catalytic reactions, should be advantageously exploited in the 954 domain of metal nanoparticle synthesis.

955

\section{Acknowledgements}

957 This work was partially supported by the EUR grant NanoX n ANR-17-EURE-0009

958 in the framework of the "Programme des Investissements d'Avenir" through the project CaSh. The authors also thank ERC Advanced Grant (MONACAT 2015694159) for financial support. 
964

965

966

967

968

969

970

971

972

973

974

975

976

977

978

979

980

981

982

983

984

985

986

987

988

989

990

991

992

993

994

995

996

997

998

999

1000

1001

1002

1003

1004

1005

1006

1007

1008

1009
1. Y. Wang, J. He, C. Liu, W. H. Chong and H. Chen, Angew. Chem. Int. Ed., 2015, 54, 2022-2051.

2. M. Chen, B. Wu, J. Yang and N. Zheng, Adv. Mater., 2012, 24, 862-879.

3. S. Luidold and H. Antrekowitsch, JOM, 2007, 59, 20-26.

4. D. Spreitzer and J. Schenk, steel research int., 2019, 90, 1900108.

5. L. Kvitek, R. Prucek, A. Panacek and J. Soukupova, in Silver Nanoparticles Health and Safety, Physicochemical Aspects of Metal Nanoparticle Preparation, IntechOpen, 2019.

6. L. D. Rampino, F. F. Nord, J. Chem. Soc., 1941, 63, 2745-2749.

7. H. Hirai, Y. Nakao, N. Toshima, K. Adachi, Chem. Lett., 1976, 5, 905-910.

8. L. Hernandez and F. F. Nord, J. Colloid Sci., 1948, 3, 363-375.

9. W. P. Dunworth and F. F. Nord, J. Am. Chem. Soc., 1950, 72, 4197-4198.

10. G. S. McGrady and G. Guilera, Chem. Soc. Rev., 2003, 32, 383-392.

11. V. K. LaMer and R. H. Dinegar, J. Am. Chem. Soc., 1950, 72, 4847-4854.

12. K. Christmann, in Encyclopedia of Interfacial Chemistry, Elsevier, 2018, pp. 213220.

13. Y. Lin and R. G. Finke, J. Am. Chem. Soc., 1994, 116, 8335-8353.

14. M. A. Watzky and R. G. Finke, J. Am. Chem. Soc., 1997, 119, 10382-10400.

15. S. Özkar and R. G. Finke, J. Am. Chem. Soc., 2005, 127, 4800-4808.

16. J. D. Aiken and R. G. Finke, J. Am. Chem. Soc., 1999, 121, 8803-8810.

17. J. Dupont and J. D. Scholten, Chem. Soc. Rev., 2010, 39, 1780-1804.

18. M. M. Giangregorio, M. Losurdo, G. V. Bianco, A. Operamolla, E. Dilonardo, A. Sacchetti, P. Capezzuto, F. Babudri and G. Bruno, J. Phys. Chem. C, 2011, 115, 19520-19528.

19. T. S. Ahmadi, Z. L. Wang, T. C. Green, A. Henglein and M. A. El-Sayed, Science, 1996, 272, 1924-1925.

20. A. R. Tao, S. Habas and P. Yang, Small, 2008, 4, 310-325.

21. Y. Xia, Y. Xiong, B. Lim and S. E. Skrabalak, Angew. Chem. Int. Ed., 2009, 48, 60-103.

22. K. M. Bratlie, H. Lee, K. Komvopoulos, P. Yang and G. A. Somorjai, Nano Lett., 2007, 7, 3097-3101.

23. K. Zhou and Y. Li, Angew. Chem. Int. Ed., 2012, 51, 602-613.

24. J. M. Petroski, Z. L. Wang, T. C. Green and M. A. El-Sayed, J. Phys. Chem. B 1998, 102, 3316-3320.

25. K. An and G. A. Somorjai, ChemCatChem, 2012, 4, 1512-1524.

26. T. Teranishi, R. Kurita and M. Miyake, Journal of Inorganic and Organometallic Polymers, 2000, 10, 145-156.

27. X. Fu, Y. Wang, N. Wu, L. Gui and Y. Tang, Langmuir, 2002, 18, 4619-4624.

28. H. Lee, S. E. Habas, S. Kweskin, D. Butcher, G. A. Somorjai and P. Yang,

Angew. Chem. Int. Ed., 2006, 45, 7824-7828.

29. C. Salzemann and C. Petit, Langmuir, 2012, 28, 4835-4841.

30. N. Aguilera-Porta, M. Calatayud, C. Salzemann and C. Petit, J. Phys. Chem. C, 2014, 118, 9290-9298.

31. L.-M. Lacroix, C. Gatel, R. Arenal, C. Garcia, S. Lachaize, T. Blon, B. WarotFonrose, E. Snoeck, B. Chaudret and G. Viau, Angew. Chem. Int. Ed., 2012, 51, 4690-4694. 
1010 32. L. Peres, D. Yi, S. Bustos-Rodriguez, C. Marcelot, A. Pierrot, P.-F. Fazzini, I.

1011

1012

1013

1014

1015

1016

1017

1018

1019

1020

1021

1022

1023

1024

1025

1026

1027

1028

1029

1030

1031

1032

1033

1034

1035

1036

1037

1038

1039

1040

1041

1042

1043

1044

1045

1046

1047

1048

1049

1050

1051

1052

1053

1054

1055

1056

1057

1058

1059

Florea, R. Arenal, L.-M. Lacroix, B. Warot-Fonrose, T. Blon and K. Soulantica,

Nanoscale, 2018, 10, 22730-22736.

33. A. R. Poerwoprajitno, L. Gloag, S. Cheong, J. J. Gooding and R. D. Tilley,

Nanoscale, 2019, 11, 18995-19011.

34. C. Amiens, B. Chaudret, D. Ciuculescu-Pradines, V. Collière, K. Fajerwerg, P.

Fau, M. Kahn, A. Maisonnat, K. Soulantica and K. Philippot, New J. Chem., 2013, 37, 3374.

35. C. Amiens, D. Ciuculescu-Pradines and K. Philippot, Coord.Chem. Rev., 2016, 308, 409-432.

36. A. Heuer-Jungermann, N. Feliu, I. Bakaimi, M. Hamaly, A. Alkilany, I.

Chakraborty, A. Masood, M. F. Casula, A. Kostopoulou, E. Oh, K. Susumu, M. H.

Stewart, I. L. Medintz, E. Stratakis, W. J. Parak, A. G. Kanaras, Chem. Rev., 2019, 119, 4819-4880.

37. K. Philippot and B. Chaudret, Comptes Rendus Chimie, 2003, 6, 1019-1034.

38. B. Cormary, F. Dumestre, N. Liakakos, K. Soulantica and B. Chaudret, Dalton

Trans., 2013, 42, 12546-12553.

39. D. Ciuculescu, C. Amiens, M. Respaud, A. Falqui, P. Lecante, R. E. Benfield, L. Jiang, K. Fauth and B. Chaudret, Chem. Mater., 2007, 19, 4624-4626.

40. J. S. Bradley, J. M. Millar, E. W. Hill, S. Behal, B. Chaudret and A. Duteil,

Faraday Disc., 1991, 92, 255-268.

41. M. R. Axet, K. Philippot, B. Chaudret, M. Cabié, S. Giorgio and C. R. Henry,

Small, 2011, 7, 235-241.

42. E. Ramirez, L. Eradès, K. Philippot, P. Lecante and B. Chaudret, Adv. Funct. Mater., 2007, 17, 2219-2228.

43. E. Ramirez, S. Jansat, K. Philippot, P. Lecante, M. Gomez, A. M. Masdeu-Bultó and B. Chaudret, J. Organomet.Chem., 2004, 689, 4601-4610.

44. M. R. Axet, S. Castillón, C. Claver, K. Philippot, P. Lecante and B. Chaudret, Eur. J. Inorg. Chem., 2008, 2008, 3460-3466.

45. C. Barrière, K. Piettre, V. Latour, O. Margeat, C.-O. Turrin, B. Chaudret and P. Fau, J. Mater. Chem., 2012, 22, 2279-2285.

46. T. O. Ely, C. Amiens, B. Chaudret, E. Snoeck, M. Verelst, M. Respaud and J.-M.

Broto, Chem. Mater., 1999, 11, 526-529.

47. F. Dumestre, B. Chaudret, C. Amiens, M. Respaud, P. Fejes, P. Renaud and P. Zurcher, Angew. Chem. Int. Ed., 2003, 42, 5213-5216.

48 T. Ayvalı, P. Lecante, P.-F. Fazzini, A. Gillet, K. Philippot and B. Chaudret,

Chem. Commun., 2014, 50, 10809-10811.

49. M. Cokoja, H. Parala, M.-K. Schröter, A. Birkner, M. W. E. van den Berg, W.

Grünert and R. A. Fischer, Chem. Mater., 2006, 18, 1634-1642.

50. M. Cokoja, H. Parala, M. K. Schröter, A. Birkner, M. W. E. van den Berg, K. V.

Klementiev, W. Grünert and R. A. Fischer, J. Mater. Chem., 2006, 16, 2420-2428.

51. L. M. Martínez-Prieto and B. Chaudret, Acc. Chem. Res., 2018, 51, 376-384.

52. M. R. Axet and K. Philippot, Chem. Rev., 2020, 120, 1085-1145.

53. C. Pan, K. Pelzer, K. Philippot, B. Chaudret, F. Dassenoy, P. Lecante and M.-J.

Casanove, J. Am. Chem. Soc., 2001, 123, 7584-7593.

54. P. Lara, K. Philippot and B. Chaudret, ChemCatChem, 2013, 5, 28-45.

55. P. Lara, O. Rivada-Wheelaghan, S. Conejero, R. Poteau, K. Philippot and B.

Chaudret, Angew. Chem. Int. Ed., 2011, 50, 12080-12084.

56. I. Favier, S. Massou, E. Teuma, K. Philippot, B. Chaudret and M. Gómez, Chem. Commun., 2008, 3296-3298. 
1060 57. K. Pelzer, O. Vidoni, K. Philippot, B. Chaudret and V. Collière, Adv. Funct. 1061 Mater., 2003, 13, 118-126.

58. P. Lignier, R. Bellabarba, R. P. Tooze, Z. Su, P. Landon, H. Ménard and W. Zhou, Cryst. Growth Des., 2012, 12, 939-942.

59. F. Leng, I. C. Gerber, P. Lecante, W. Bacsa, J. Miller, J. R. Gallagher, S.

Moldovan, M. Girleanu, M. R. Axet and P. Serp, RSC Adv., 2016, 6, 69135-69148. 60. E. Bresó-Femenia, C. Godard, C. Claver, B. Chaudret and S. Castillón, Chem. Commun., 2015, 51, 16342-16345.

61. T. Pery, K. Pelzer, G. Buntkowsky, K. Philippot, H.-H. Limbach and B. Chaudret, ChemPhysChem, 2005, 6, 605-607.

62. R. González-Gómez, L. Cusinato, C. Bijani, Y. Coppel, P. Lecante, C. Amiens, I. del Rosal, K. Philippot and R. Poteau, Nanoscale, 2019, 11, 9392-9409.

63. J. García-Antón, M. R. Axet, S. Jansat, K. Philippot, B. Chaudret, T. Pery, G. Buntkowsky and H.-H. Limbach, Angew. Chem. Int. Ed., 2008, 47, 2074-2078.

64. T. Gutmann, B. Walaszek, X. Yeping, M. Wächtler, I. del Rosal, A. Grünberg, R. Poteau, R. Axet, G. Lavigne, B. Chaudret, H.-H. Limbach and G. Buntkowsky, J. Am. Chem. Soc., 2010, 132, 11759-11767.

65. L. A. Truflandier, I. Del Rosal, B. Chaudret, R. Poteau and I. C. Gerber, ChemPhysChem, 2009, 10, 2939-2942.

66. F. Schröder, D. Esken, M. Cokoja, M. W. E. van den Berg, O. I. Lebedev, G. Van Tendeloo, B. Walaszek, G. Buntkowsky, H.-H. Limbach, B. Chaudret and R. A. Fischer, J. Am. Chem. Soc., 2008, 130, 6119-6130.

67. D. González-Gálvez, P. Nolis, K. Philippot, B. Chaudret and P. W. N. M. van Leeuwen, ACS Catal., 2012, 2, 317-321.

68. Y. Min, H. Nasrallah, D. Poinsot, P. Lecante, Y. Tison, P. Roblin, A. Falqui, R.

Poteau, M. R. Axet and P. Serp, Chem. Mater., 2020, 14, 2365-2378.

69. G. Pieters, C. Taglang, E. Bonnefille, T. Gutmann, C. Puente, J.-C. Berthet, C. Dugave, B. Chaudret and B. Rousseau, Angew. Chem. Int. Ed., 2014, 53, $230-$ 234.

70. C. Taglang, L. M. Martínez-Prieto, I. del Rosal, L. Maron, R. Poteau, K. Philippot, B. Chaudret, S. Perato, A. Sam Lone, C. Puente, C. Dugave, B. Rousseau and G. Pieters, Angew. Chem. Int. Ed., 2015, 54, 10474-10477.

71. L. Cusinato, L. M. Martínez-Prieto, B. Chaudret, I. del Rosal and R. Poteau, Nanoscale, 2016, 8, 10974-10992.

72. L. M. Martínez-Prieto, S. Carenco, C. H. Wu, E. Bonnefille, S. Axnanda, Z. Liu, P. F. Fazzini, K. Philippot, M. Salmeron and B. Chaudret, ACS Catal., 2014, 4, 3160-3168.

73. F. Leng, I. C. Gerber, P. Lecante, S. Moldovan, M. Girleanu, M. R. Axet and P. Serp, ACS Catal., 2016, 6, 6018-6024.

74. I. M. L. Billas, A. Chatelain and W. A. de Heer, Science, 1994, 265, 1682-1684. 75. M. Respaud, J. M. Broto, H. Rakoto, A. R. Fert, L. Thomas, B. Barbara, M. Verelst, E. Snoeck, P. Lecante, A. Mosset, J. Osuna, T. O. Ely, C. Amiens and B. Chaudret, Phys. Rev. B, 1998, 57, 2925-2935.

76. J. Osuna, D. de Caro, C. Amiens, B. Chaudret, E. Snoeck, M. Respaud, J.-M.

Broto and A. Fert, J. Phys. Chem., 1996, 100, 14571-14574.

77. N. Cordente, C. Amiens, B. Chaudret, M. Respaud, F. Senocq and M.-J.

Casanove, Journal of Applied Physics, 2003, 94, 6358-6365.

78. F. Dumestre, B. Chaudret, C. Amiens, M.-C. Fromen, M. J. Casanove, P. Renaud, P. Zurcher, Angew. Chem. Int. Ed. 2002, 41, 4286-4289. 
1109 79. D. Ciuculescu, F. Dumestre, M. Comesaña-Hermo, B. Chaudret, M. Spasova, M.

1110 Farle and C. Amiens, Chem. Mater., 2009, 21, 3987-3995.

80. B. Cormary, T. Li, N. Liakakos, L. Peres, P.-F. Fazzini, T. Blon, M. Respaud, A. J. Kropf, B. Chaudret, J. T. Miller, E. A. Mader and K. Soulantica, J. Am. Chem. Soc., 2016, 138, 8422-8431.

81. F. Dumestre, B. Chaudret, C. Amiens, P. Renaud, P. Fejes, Science, 2004, 303, 821-823.

82. F. Wetz, K. Soulantica, M. Respaud, A. Falqui and B. Chaudret, Mat. Sci. Eng. C, 2007, 27, 1162-1166.

83. M. He, L. Protesescu, R. Caputo, F. Krumeich and M. V. Kovalenko, Chem. Mater., 2015, 27, 635-647.

84. O. Margeat, F. Dumestre, C. Amiens, B. Chaudret, P. Lecante and M. Respaud, Progress in Solid State Chemistry, 2005, 33, 71-79.

85. L.-M. Lacroix, S. Lachaize, A. Falqui, M. Respaud and B. Chaudret, J. Am.

Chem. Soc., 2009, 131, 549-557.

86. N. Liakakos, B. Cormary, X. Li, P. Lecante, M. Respaud, L. Maron, A. Falqui, A. Genovese, L. Vendier, S. Koïnis, B. Chaudret and K. Soulantica, J. Am. Chem. Soc., 2012, 134, 17922-17931.

87. N. Liakakos, C. Gatel, T. Blon, T. Altantzis, S. Lentijo-Mozo, C. Garcia-Marcelot, L.-M. Lacroix, M. Respaud, S. Bals, G. Van Tendeloo and K. Soulantica, Nano Lett., 2014, 14, 2747-2754.

88. C. Garnero, M. Lepesant, C. Garcia-Marcelot, Y. Shin, C. Meny, P. Farger, B. Warot-Fonrose, R. Arenal, G. Viau, K. Soulantica, P. Fau, P. Poveda, L.-M. Lacroix and B. Chaudret, Nano Lett., 2019, 19, 1379-1386.

89. S. Mourdikoudis, V. Collière, C. Amiens, P. Fau and M. L. Kahn, Langmuir, 2013, 29, 13491-13501.

90. G. L. Drisko, C. Gatel, P.-F. Fazzini, A. Ibarra, S. Mourdikoudis, V. Bley, K.

Fajerwerg, P. Fau and M. Kahn, Nano Lett., 2018, 18, 1733-1738.

91. X. Liang, N. Liu, H. Qiu, C. Zhang, D. Mei and B. Chen, Phys. Chem. Chem.

Phys., 2017, 19, 26718-26727.

92. X. Wang, N. Liu, C. Dai, R. Xu, B. Wu, G. Yu and B. Chen, J. Phys. Chem. C, 2020, 124, 2160-2170.

93. A. P. LaGrow, B. Ingham, S. Cheong, G. V. M. Williams, C. Dotzler, M. F. Toney, D. A. Jefferson, E. C. Corbos, P. T. Bishop, J. Cookson and R. D. Tilley, J. Am. Chem. Soc., 2012, 134, 855-858.

94. A. P. LaGrow, S. Cheong, J. Watt, B. Ingham, M. F. Toney, D. A. Jefferson and

R. D. Tilley, Adv. Mater., 2013, 25, 1552-1556.

95. A. R. Poerwoprajitno, L. Gloag, J. Watt, S. Cychy, S. Cheong, P. V. Kumar, T. M. Benedetti, C. Deng, K.-H. Wu, C. E. Marjo, D. L. Huber, M. Muhler, J. J. Gooding, W. Schuhmann, D.-W. Wang and R. D. Tilley, Angew. Chem. Int. Ed., 2020, 59, $15487-15491$.

96. Y. Bing, H. Liu, L. Zhang, D. Ghosh and J. Zhang, Chem. Soc. Rev., 2010, 39, 2184-2202.

97. R. Xie, Y. Pan and H. Gu, RSC Adv., 2015, 5, 16497-16500.

98. J. Mao, W. Chen, D. He, J. Wan, J. Pei, J. Dong, Y. Wang, P. An, Z. Jin, W. Xing, H. Tang, Z. Zhuang, X. Liang, Y. Huang, G. Zhou, L. Wang, D. Wang and Y. Li, Sci. Adv., 2017, 3, e1603068.

99. R. K. Ramamoorthy, A. Viola, B. Grindi, J. Peron, C. Gatel, M. Hytch, R. Arenal, L. Sicard, M. Giraud, J.-Y. Piquemal and G. Viau, Nano Lett., 2019, 19, 9160-9169. 100 J. Wu, Y. Huang, W. Ye and Y. Li, Adv. Sci., 2017, 4, 1700194. 
1159 101. R. H. Crabtree, in The Organometallic Chemistry of the Transition Metals, John

1160 Wiley \& Sons, Inc., Hoboken, NJ, USA, 2005, pp. 87-124.

1161

1162

102. S. S. Sung and R. Hoffmann, J. Am. Chem. Soc., 1985, 107, 578-584.

1163

103. S. Y. Hwang, M. Zhang, C. Zhang, B. Ma, J. Zheng and Z. Peng, Chem.

Commun., 2014, 50, 14013-14016.

1164

1165

104. J. Rabo, Journal of Catalysis, 1978, 53, 295-311.

1166

105. G. P. Valença and E. S. Gonçalves, in Studies in Surface Science and

Catalysis, Elsevier, 2001, vol. 133, pp. 399-407.

1167

106. A. Duteil, R. Queau, B. Chaudret, R. Mazel, C. Roucau and J. S. Bradley, Chem. Mater., 1993, 5, 341-347.

1169

107. C. Amiens, D. de Caro, B. Chaudret, J. S. Bradley, R. Mazel and C. Roucau, J. Am. Chem. Soc., 1993, 115, 11638-11639.

1171

108. S. Ishi and Y. Ohno, Surf. Sci., 1985, 161, 349-372.

109. T. M. Duncan, K. W. Zilm, D. M. Hamilton and T. W. Root, J. Phys. Chem. 1989, 93, 2583-2590.

110. F. Novio, K. Philippot and B. Chaudret, Catal Lett, 2010, 140, 1-7.

111. F. Novio, D. Monahan, Y. Coppel, G. Antorrena, P. Lecante, K. Philippot and B. Chaudret, Chem. Eur. J., 2014, 20, 1287-1297.

112. J. S. Bradley, E. W. Hill, B. Chaudret and A. Duteil, Langmuir, 1995, 11, 693695.

113. X. Cheng, Z. Shi, N. Glass, L. Zhang, J. Zhang, D. Song, Z.-S. Liu, H. Wang and J. Shen, J. Power Sources, 2007, 165, 739-756.

1181

114. Y. Yu, Z. Luo, Y. Yu, J. Y. Lee and J. Xie, ACS Nano, 2012, 6, 7920-7927.

115. T. Chen and J. Xie, Chem. Rec., 2016, 16, 1761-1771.

116. N. Goswami, Q. Yao, T. Chen and J. Xie, Coord. Chem. Rev. 2016, 329, 1-15.

117. V. Latour, A. Maisonnat, Y. Coppel, V. Collière, P. Fau and B. Chaudret, Chem. Commun., 2010, 46, 2683-2685.

118. P.-J. Debouttière, Y. Coppel, P. Behra, B. Chaudret and K. Fajerwerg, Gold Bull, 2013, 46, 291-298.

119. J. Pal and T. Pal, Nanoscale, 2015, 7, 14159-14190.

120. J. Wu, L. Qi, H. You, A. Gross, J. Li and H. Yang, J. Am. Chem. Soc., 2012, 134, 11880-11883.

121. F. Nosheen, N. Wasfi, S. Aslam, T. Anwar, S. Hussain, N. Hussain, S. N. Shah, N. Shaheen, A. Ashraf, Y. Zhu, H. Wang, J. Ma, Z. Zhang and W. Hu, Nanoscale, 2020, 12, 4219-4237.

122. J. W. Hong, Y. Kim, D. H. Wi, S. Lee, S.-U. Lee, Y. W. Lee, S.-I. Choi and S. W. Han, Angew. Chem. Int. Ed., 2016, 55, 2753-2758.

123. L. Zhao, C. Xu, H. Su, J. Liang, S. Lin, L. Gu, X. Wang, M. Chen and N. Zheng, Adv. Sci., 2015, 2, 1500100.

124. C. Wang, H. Daimon, T. Onodera, T. Koda and S. Sun, Angew. Chem. Int. Ed., 2008, 47, $3588-3591$

125. S. I. Lim, I. Ojea-Jiménez, M. Varon, E. Casals, J. Arbiol and V. Puntes, Nano Lett., 2010, 10, 964-973.

126. J. Zhang and J. Fang, J. Am. Chem. Soc., 2009, 131, 18543-18547.

127. J. Wu, A. Gross and H. Yang, Nano Lett., 2011, 11, 798-802.

128. Y. Kang, X. Ye and C. B. Murray, Angewandte Chemie, 2010, 122, 6292-6295.

129. B. Wu, N. Zheng and G. Fu, Chem. Commun., 2011, 47, 1039-1041.

130. M. Xie, Z. Lyu, R. Chen and Y. Xia, Chem. Eur. J., 2020, DOI:

10.1002/chem.202003202. 
131. Y. Wang, Z. Sun, A. Kumbhar, Z. Luo, C. Wang, J. Zhang, N. Porter, C. Xu, K. Sun, B. Martens and J. Fang, Chem. Commun., 2013, 49, 3955-3957. 132. Y. Chen, Z. Fan, Z. Zhang, W. Niu, C. Li, N. Yang, B. Chen and H. Zhang, Chem. Rev., 2018, 118, 6409-6455.

133. U. Schlotterbeck, C. Aymonier, R. Thomann, H. Hofmeister, M. Tromp, W. Richtering and S. Mecking, Adv. Funct. Mater., 2004, 14, 999-1004.

134. P. F. Siril, L. Ramos, P. Beaunier, P. Archirel, A. Etcheberry and H. Remita, Chem. Mater., 2009, 21, 5170-5175.

135. X. Huang, S. Tang, X. Mu, Y. Dai, G. Chen, Z. Zhou, F. Ruan, Z. Yang and N. Zheng, Nature Nanotech, 2011, 6, 28-32.

1218 136. H. Li, G. Chen, H. Yang, X. Wang, J. Liang, P. Liu, M. Chen and N. Zheng, Angew. Chem. Int. Ed., 2013, 52, 8368-8372.

137. X. Yin, X. Liu, Y.-T. Pan, K. A. Walsh and H. Yang, Nano Lett., 2014, 14, 71887194.

138. Y. Dai, X. Mu, Y. Tan, K. Lin, Z. Yang, N. Zheng and G. Fu, J. Am. Chem. Soc., 2012, 134, 7073-7080.

139. A. Bordet, L.-M. Lacroix, P.-F. Fazzini, J. Carrey, K. Soulantica and B.

Chaudret, Angew. Chem. Int. Ed., 2016, 55, 15894-15898.

140. J. M. Asensio, A. B. Miguel, P. Fazzini, P. W. N. M. van Leeuwen and B. Chaudret, Angew. Chem. Int. Ed., 2019, 58, 11306-11310.

141. A. Meffre, B. Mehdaoui, V. Kelsen, P. F. Fazzini, J. Carrey, S. Lachaize, M. Respaud and B. Chaudret, Nano Lett., 2012, 12, 4722-4728.

142. K. Loizou, S. Mourdikoudis, A. Sergides, M. O. Besenhard, C. Sarafidis, K. Higashimine, O. Kalogirou, S. Maenosono, N. T. K. Thanh and A. Gavriilidis, ACS Appl. Mater. Interfaces, 2020, 12, 28520-28531.

143. P. Ruiz, Hydrogen: applications and safety considerations, Matgas 2000 AIE, Bellaterra, Barcelona, 2015 12871-12934. 